\title{
High fructose exposure modifies the amount of adipocyte- secreted microRNAs into extracellular vesicles in supernatants and plasma
}

\begin{abstract}
Adrián Hernández-Díazcouder ${ }^{1,2}$, Javier González-Ramírez ${ }^{3}$, Abraham Giacoman-Martínez ${ }^{4}$, Guillermo CardosoSaldaña $^{5}$, Eduardo Martínez-Martínez ${ }^{6}$, Horacio Osorio-Alonso ${ }^{7}$, Ricardo Márquez-Velasco ${ }^{2}$, José L SánchezGloria $^{2}$, Yaneli Juárez-Vicuña ${ }^{2}$, Guillermo Gonzaga ${ }^{7}$, Laura Gabriela Sanchez-Lozada ${ }^{7}$, Julio César Almanza-Pérez ${ }^{4}$ , Fausto Sánchez-Muñoz ${ }^{\text {Corresp. } 2}$

1 Posgrado en Biología Experimental, Universidad Autónoma Metropolitana-Iztapalapa, Ciudad de México, Ciudad de México, México

2 Departamento de Inmunología, Instituto Nacional de Cardiología Ignacio Chávez, Ciudad de México, Ciudad de México, México

3 Laboratorio de Biología Celular, Facultad de Enfermería, Universidad Autónoma de Baja California Campus Mexicali, Mexicali, Baja California, Mexico

4 Laboratorio de Farmacología, Departamento de Ciencias de la Salud, Universidad Autónoma Metropolitana-Iztapalapa, Ciudad de México, Ciudad de México, México

5 Departamento de Endocrinología, Instituto Nacional de Cardiología Ignacio Chávez, Ciudad de México, Ciudad de México, México

6 Laboratorio de Comunicación Celular y Vesículas Extracelulares, Instituto Nacional de Medicina Genómica, Ciudad de México, Ciudad de México, México

7 Departamento de Fisiopatología Cardio-Renal, Instituto Nacional de Cardiología Ignacio Chávez, Ciudad de México, Ciudad de México, México

Corresponding Author: Fausto Sánchez-Muñoz

Email address: fausto.sanchez@cardiologia.org.mx
\end{abstract}

Background. High fructose exposure induces metabolic and endocrine responses in adipose tissue. Recent evidence suggests that microRNAs in extracellular vesicles are endocrine signals secreted by adipocytes. Fructose exposure on the secretion of microRNA by tissues and cells is poorly studied. Thus, the aim of this study was to evaluate the effect of fructose exposure on the secretion of selected microRNAs in extracellular vesicles from 3T3-L1 cells and plasma from Wistar rats. Methods. 3T3-L1 cells were exposed to $550 \mu \mathrm{M}$ of fructose or standard media for four days, microRNAs levels were determined in extracellular vesicles of supernatants and cells by RT-qPCR. Wistar rats were exposed to either $20 \%$ fructose drink or tap water for eight weeks, microRNAs levels were determined in extracellular vesicles of plasma and adipose tissue by RT-qPCR. Results. This study showed that fructose exposure increased the total number of extracellular vesicles released by 3T3-L1 cells $(p=0.0001)$. The levels of miR-143-5p were increased in extracellular vesicles of 3T3-L1 cells exposed to fructose $(p=0.0286)$, whereas miR-223-3p levels were reduced $(p=0.0286)$. Moreover, in plasma-derived extracellular vesicles, miR-143-5 $p$ was higher in fructose-fed rats $(p=0.001)$, whereas miR-223-3p $(p=0.022)$, miR-342-3p ( $p=0.0011)$, miR-140-5p ( $p=0.0129)$ and miR-146b-5p $(p=0.0245)$ were lower. Conclusion. Fructose exposure modifies the levels of microRNAs in extracellular vesicles in vitro and in vivo. Particularly, fructose exposure increases miR-143-5p, while decreases 
miR-223-3p and miR-342-3p. 


\section{High fructose exposure modifies the amount of}

2 adipocyte-secreted microRNAs into extracellular

3 vesicles in supernatants and plasma.

4

Adrián Hernández-Díazcouder ${ }^{1,2}$, Javier González-Ramírez ${ }^{3}$, Abraham Giacoman-Martínez ${ }^{4}$, Guillermo Cardoso-Saldaña ${ }^{5}$, Eduardo Martínez-Martínez ${ }^{6}$, Horacio Osorio-Alonso ${ }^{7}$, Ricardo

Márquez-Velasco ${ }^{1}$, José L Sánchez-Gloria ${ }^{1}$, Yaneli Juárez-Vicuña ${ }^{1}$, Guillermo Gonzaga ${ }^{7}$, Laura

Gabriela Sánchez-Lozada ${ }^{7}, J_{1}$ lio César Almanza-Pérez ${ }^{4}$ and Fausto Sánchez-Muñoz ${ }^{*}$

1. Departamento de Inmunología, Instituto Nacional de Cardiología Ignacio Chávez, Ciudad de México, México.

2. Posgrado en Biología Experimental, Universidad Autónoma Metropolitana-Iztapalapa, Ciudad de México, México.

3. Laboratorio de Biología Celular, Facultad de Enfermería, Universidad Autónoma de Baja California Campus Mexicali, Mexicali, México.

4. Laboratorio de Farmacología, Departamento de Ciencias de la Salud, Universidad Autónoma Metropolitana-Iztapalapa, Ciudad de México, México.

5. Departamento de Endocrinología, Instituto Nacional de Cardiología Ignacio Chávez, Ciudad de México, México.

6. Laboratorio de Comunicación Celular y Vesículas Extracelulares, Instituto Nacional de Medicina Genómica, Ciudad de México, México.

7. Departamento de Fisiopatología Cardio-Renal, Instituto Nacional de Cardiología Ignacio Chávez, Ciudad de México, México.

Corresponding Author:

Fausto Sánchez-Muñoz ${ }^{1}$

Juan Badiano 1, Belisario Domínguez Sección 16, Tlalpan, Mexico City, 14080, Mexico. Email address: fausto22@yahoo.com

\section{Abstract}

Background. High fructose exposure induces metabolic and endocrine responses in adipose tissue. Recent evidence suggests that microRNAs in extracellular vesicles are endocrine signals secreted by adipocytes. The effect of fructose exposure on the secretion of microRNA by tissues and cells is poorly studied. The aim of this study was to evaluate the effect of fructose exposure on the secretion of selected microRNAs in extracellular vesicles from 3T3-L1 cells and plasma from Wistar rats. 
55

56

57

58

59

60

Methods. 3T3-L1 cells were exposed to $550 \mu \mathrm{M}$ of fructose or standard media for four days, microRNAs levels were determined in extracellular vesicles of supernatants and cells by RTqPCR. Wistar rats were exposed to either $20 \%$ fructose drink or tap water for eight weeks, microRNAs levels were determined in extracellular vesicles of plasma and adipose tissue by RTqPCR.

Results. This study showed that fructose exposure increased the total number of extracellular vesicles released by $3 \mathrm{~T} 3-\mathrm{L} 1$ cells $(p=0.0001)$. The levels of miR-143-5p were increased in extracellular vesicles of 3T3-L1 cells exposed to fructose ( $p=0.0286$ ), whereas miR-223-3p levels were reduced $(p=0.0286)$. Moreover, in plasma-derived extracellular vesicles, miR-143-5p was higher in fructose-fed rats $(p=0.001)$, whereas miR-223-3p ( $p=0.022)$, miR-342-3p $(p=0.0011), \operatorname{miR}-140-5 \mathrm{p}(p=0.0129)$ and $\mathrm{miR}-146 \mathrm{~b}-5 \mathrm{p}(p=0.0245)$ were lower.

Conclusion. Fructose exposure modifies the levels of microRNAs in extracellular vesicles in vitro and in vivo. Particularly, fructose exposure increases miR-143-5p, while decreases miR223-3p and miR-342-3p.

\section{Introduction}

Over the past decades, sucrose and high fructose corn syrup have been used as the main fructose source in processed foods, including sweetened beverages. The high fructose intake promotes several metabolic abnormalities, including glucose intolerance, hypertension, hyperlipidemia, non-alcoholic fatty liver disease, chronic low-grade inflammation, adipose tissue expansion, and an imbalance in adipokine secretion from adipose tissue (Legeza et al., 2017; Hernández-Díazcouder et al., 2019). Moreover, it has been reported that high fructose exposure affects adipose tissue through mechanisms involving adipocyte function in humans, murine, and cellular models (Zubiría et al., 2016b; Pu \& Veiga-Lopez, 2017; Hernández-Díazcouder et al., 2019). Although, the adipocytic cellular response to high fructose exposure has been explored, its endocrine activity has not been fully explored.

Several studies have demonstrated that adipose tissue produces adipokines that regulate lipid storage via endocrine and paracrine signals (Perez-Diaz et al., 2018; Hörbelt et al., 2019). For example, polymerase I and transcription release factor is secreted from adipocytes and it induces lipid accumulation in both hepatocytes and adipocytes (Perez-Diaz et al., 2018). Recently microRNAs (miRNAs) have emerged as novel endocrine and paracrine signals (Peng \& Wang, 2018). Adipocytes secrete miRNAs in exosomes and microvesicles, which are two subtypes of extracellular vesicles (EVs) that differ in size and molecular content (Connolly et al., 2015; Durcin et al., 2017). Moreover, it has been described that adipocytes release two types of EVs: small EVs (below $100 \mathrm{~nm}$ ) and large EVs (100-200 nm) (Durcin et al., 2017). Recent studies have demonstrated that specific miRNAs transported in EVs participate as endocrine signals involved in the regulation of several cellular processes, including adipogenesis (Huang-Doran, Zhang \& Vidal-Puig, 2017; Thomou et al., 2017). The transfer of miR-450a-5p through EVs activates adipogenesis in adipose tissue-derived stem cells (Zhang et al., 2017). Moreover, it has 
79 been demonstrated that fructose exposure modulates levels of miRNAs in EVs. For example,

80 sucrose-fed rats showed an increase in levels of miRNAs related to inflammation in EVs such as

81 miR-21-5p and miR-223-3p (Brianza-Padilla et al., 2016). However, there is no evidence that

82 fructose regulates the levels of adipocyte-related miRNAs in EVs.

83 Several studies have shown that miRNAs regulate the translation of several genes in adipocytes

84 (Engin, 2017; Gebert \& MacRae, 2019). For example, it has been demonstrated that miR-140-5p 85 and miR-450a-5p induce adipocyte differentiation (Wang et al., 2016; Zhang et al., 2016, 2017).

86 In addition to being involved in adipogenesis (Jeong Kim et al., 2009; Wang et al., 2011, 2015b;

87 Kim et al., 2012; Ahn et al., 2013; Chen et al., 2014a; Guan et al., 2015a; Shi et al., 2015a), miR-

$88 \quad 342-3 p$ and miR-21-5p are related to the development of obesity. The miR-342-3p is up-

89 regulated during the development of obesity (Chartoumpekis et al., 2012), and T2DM patients

90 (Collares et al., 2013), and miR-21-5p is increased in adipose tissue of obese diabetic subjects

91 (Guglielmi et al., 2017). Additionally, miR-223-3p is implicated in the inflammatory response

92 (Li et al., 2010) and has been linked to metabolic alterations related to obesity (Lu, Buchan \&

93 Cook, 2010; Zhuang et al., 2012; Sud et al., 2017). miR-148a-5p is regulated by inflammatory

94 cytokines and adipokines (Shi et al., 2016). Finally, miR-143-5p is related to the induction of

95 insulin resistance by regulating insulin signaling (Jordan et al., 2011). Also, this miRNA

96 promotes lipid accumulation in adipocytes (Xie, Lim \& Lodish, 2009; Wang et al., 2011), and

97 miR-146b-5p regulates glucose homeostasis by downregulation of IRS1 in preadipocytes (Zhu et

98 al., 2018). A recent study found an increase in levels of miR-21-5p in the plasma of fructose-fed

99 mice (Engin, 2017). In summary, this set of miRNAs display a clear role in obesity, T2DM, and

100 adipogenesis (Table 1). Because these miRNAs are related to adipocyte functions, and it is

101 known that fructose could modify endocrine responses, we hypothesized that fructose modifies

102 the secretion of miR-143-5p, miR-140-5p, miR-146b-5p, miR-223-3p, miR-21-5p, miR-342-3p,

103 miR-148a-5p and miR-450a-5p through EVs derived from 3T3-L1 cells and rat plasma. Thus,

104 the aim of this study was to evaluate the effect of fructose exposure on the secretion of selected

105 microRNAs in extracellular vesicles from 3T3-L1 cells and plasma from Wistar rats.

106

\section{Materials \& Methods}

108

109

110

111

112

113

114

115

116

117

118

\section{T3-L1 cell culture}

3T3-L1 cells were acquired from ATCC and cultured in six-well plates $\left(8 \times 10^{4}\right.$ cells per well) with Dulbecco's Modified Eagles Medium (DMEM, Gibco, Grand Island, NY, USA) supplemented with $0.1 \mathrm{mM} \mathrm{L}$-glutamine, $1 \mathrm{mM}$ sodium pyruvate, $0.1 \mathrm{mM}$ nonessential amino acids, $1 \%$ gentamicin and $10 \%$ fetal bovine serum (FBS) until they reached confluence. For EVs collection experiments, FBS was ultracentrifuged at 118,000 $\mathrm{g}$ for $18 \mathrm{~h}$ (45 Ti rotor, Beckman Coulter) to remove the EVs (Shelke et al., 2014). After reaching confluence, cells were incubated with differentiation cocktail: $0.5 \mathrm{mM}$ 3-isobutyl-1-methylxanthine, $0.25 \mu \mathrm{M}$ dexamethasone and $0.8 \mu \mathrm{M}$ bovine insulin in DMEM with $10 \%$ FBS. Two days later, the culture medium was replaced with DMEM supplemented 10\% EV-depleted FBS with $550 \mu \mathrm{M}$ fructose (Sigma- 
119 Aldrich; MO, USA). A previous study demonstrated that $550 \mu \mathrm{M}$ of fructose promotes

120 adipogenesis in 3T3-L1 cells (Du \& Heaney, 2012a). Afterward, the culture medium was

121 replaced every two days until the fourth day when the culture medium was recovered, and cells

122 were harvested. All cultures were maintained under humidified conditions and incubated at $5 \%$

$123 \mathrm{CO}_{2}$ and $37^{\circ} \mathrm{C}$.

124

125

126

127

128

129

130

131

132

133

134

135

136

137

138

139

140

141

142

143

144

145

146

147

148

149

150

151

152

153

154

155

156

157

158

\section{Animals}

Rats were raised in the animal facilities at Instituto Nacional de Cardiología Ignacio Chávez and were handled following the regulations of the Mexican Official Norm (NOM-062-ZOO1999) for production, care, and use of laboratory animals. Twenty male Wistar rats of eight weeks of age and weighing 100-120g were randomly allocated to two groups. All animals were housed under artificial 12-hour light/dark cycles and a temperature of $22^{\circ} \mathrm{C}$. The control group allocated in a cage $(n=6)$ had free access to tap water, and the fructose group $(n=14)$ allocated in three cages (five rats per cage) had to access to a $20 \%$ fructose solution (w/v) as their only liquid source. Both groups received a standard rodent diet (Laboratory Rodent Diet 5001: protein $24.1 \%$, fat $11.4 \%$, fiber (crude) $5.2 \%$ carbohydrates $48.7 \%$; Starch $21.9 \%$ sucrose $3.15 \%$, for Nutrition International, Brentwood, MO, USA) for eight weeks. Rats were given ad libitum access to diet. The euthanasia was carried out by an injection of pentobarbital is approved by NOM-062-ZOO-1991. The main project was approved by the Internal Animal Care and Use Committee of Instituto Nacional de Cardiología Ignacio Chávez (Permit No INC/CICUAL/009/2018).

\section{Biochemical Measurements}

After eighth weeks, all rats were weighed, fasted for six hours, and sacrificed. Blood samples were collected by cardiac puncture under terminal anesthesia (pentobarbital), using $\mathrm{K}+$ EDTA as an anticoagulant. Epididymal adipose tissue was collected and weighed. Plasma was obtained by blood centrifugation $\left(2000 \mathrm{xg}\right.$ for 15 minutes at $\left.4^{\circ} \mathrm{C}\right)$ and stored at $-70^{\circ} \mathrm{C}$ until needed. Glucose (DCL- glucose oxidase Diagnostic Chemical Limited de Mexico, Mexico), triglycerides, total cholesterol (SPINREACT cholesterol-LQ and triglycerides-LQ; Spinreact S.A. Girona, Spain) and HDL-C (Hitachi 902 analyzer: Hitachi LTD, Tokyo, Japan) were determined using standard enzymatic procedures. The accuracy and precision of the biochemical measures are provided in a previous report (Brianza-Padilla et al., 2016). Insulin resistance was estimated using the homeostasis model assessment method (HOMA). It was calculated using the following formula: Plasma glucose $(\mathrm{mg} / \mathrm{dL}) \times$ fasting plasma insulin $(\mathrm{IU} \mathrm{mg} / \mathrm{L})$ in the fasting state divided by 405 (Matthews et al., 1985).

\section{Cytokines and Insulin Resistance Measurements}

Plasma leptin, insulin, and IL-1 $\beta$ were determined using Milliplex MAP rat adipokine magnetic bead panel kit (Millipore; Billerica, MA, USA) following the manufacturer's indications. Proteins were analyzed using a Luminex MAGPIX system (Luminex Corporation; 
159

160

161

162

163

164

165

166

167

168

169

170

171

172

173

174

175

176

177

178

179

180

181

182

183

184

185

186

187

188

189

190

191

192

193

194

195

196

197

Houston, TX, USA) and Milliplex Analyst software (Millipore; St. Charles, MO, USA). Plasma adiponectin was determined using the ELISA kit for Rat Adiponectin (Millipore; Billerica, MA, USA) following the manufacturer's indications.

\section{Measurement of adipocyte size}

Epididymal adipose tissue fixed in 10\% formalin (Sigma-Aldrich; MO, USA) was used for hematoxylin and eosin staining. The adipocyte area of epididymal adipose tissue was analyzed using ImageJ software (National Institutes of Health, Bethesda, MD, USA) from hematoxylin and eosin-stained adipose tissue sections. The mean adipocyte surface area was calculated from 500 cells/rat.

\section{RNA Isolation of 3T3-L1 preadipocytes and rat epididymal adipose tissue}

Total RNA was extracted from 3T3-L1 cells and $100 \mathrm{mg}$ of rat epididymal adipose tissue by Tripure method following the manufacturer's protocol (Roche; Basel, Switzerland). miR-143-5p, miR-140-5p, miR-146b-5p, miR-223-3p, miR-21-5p, miR-342-3p, miR-148a-5p and miR-450a$5 p$ were determined using two-step RT-qPCR with RT-primer specific assay in combination with TaqMan probes (Applied Biosystems; CA, USA). The RNA isolated was immediately converted to cDNA, as described below.

\section{Extracellular vesicles size and number estimation}

NanoSight NS300 was used to determine vesicle size and concentration (Malvern Instruments Ltd; Malvern, UK). Previously, the supernatant or plasma was centrifuged (10000 x $g$ for $30 \mathrm{~min}$ at $4^{\circ} \mathrm{C}$ ) to remove cell debris, and the supernatant was recovered. Briefly, the samples were diluted 4.5:500 in PBS, and each sample was injected into the NanoSight chamber. The camera gain was set at a constant value of 10 , and the threshold value for vesicle detection was set at 5 .

\section{Western blot analysis}

After the fourth day of fructose treatment, cell culture media was collected and centrifuged at $400 \mathrm{x} g$ for $10 \mathrm{~min}$ to remove cells. The supernatant was centrifuged at $2000 \mathrm{x} g$ for $20 \mathrm{~min}$ to remove cell debris, and the resultant supernatant was stored at $-70{ }^{\circ} \mathrm{C}$ until further use. The samples were thawed at $4^{\circ} \mathrm{C}$. Two $\mathrm{mL}$ of a PEG 8000 solution $(50 \% \mathrm{w} / \mathrm{v})$ was added per each $10 \mathrm{~mL}$ of sample and incubated overnight at $4^{\circ} \mathrm{C}$. The samples were centrifuged at $1500 \mathrm{x}$, and the pellet was resuspended in $2.7 \mathrm{~mL}$ of PBS. The sample was pipetted into $13 \mathrm{x} 51 \mathrm{~mm}$ tubes for ultracentrifugation (Optima MAX, Beckman Coulter) at 118,000 x g (53,000 rpm, k-factor 56.7) at $4^{\circ} \mathrm{C}$ in a fix angle rotor (TLA 100.3, Beckman Coulter; CA, USA) for 39 minutes. The resultant pellet was resuspended in $50 \mu \mathrm{L}$ of RIPA buffer supplemented with 1x protease inhibitors cocktail and 1x EDTA (Halt Protease Inhibitor Single-Use Cocktail, Thermo Scientific; MA, USA). A Tricine-SDS-PAGE method was used to separate proteins. After 
198 blotting, membranes were incubated overnight with rabbit anti-ANXA2 (Abcam, ab178677) at

199

200

201

202

203

204

205

206

207

208

209

210

211

212

213

214

215

216

217

218

219

220

221

222

223

224

225

226

227

228

229

230

231

232

233

234

235

236

1:5,000 and rabbit anti-CD63 (Abcam, ab193349) at 1:2,000.

\section{RNA Isolation of extracellular vesicles of supernatants of preadipocytes and rat plasma}

$600 \mu \mathrm{L}$ of cell supernatants and rat plasma were centrifuged $\left(10000 \mathrm{x} g\right.$ for $30 \mathrm{~min}$ at $\left.4{ }^{\circ} \mathrm{C}\right)$ to remove cell debris, and the supernatant was recovered. For RNA isolation of EVs the exoRNeasy serum/plasma midi kit (Qiagen; Hilden, Germany) was used. During the RNA purification step, the same amount of cel-miR-39 spike-in control was added (Qiagen; Hilden, Germany) according to the provider recommendations and previous publication (Enderle et al., 2015). The RNA isolated from EVs was immediately converted to cDNA, as described below.

\section{miRNAs determination by RT-qPCR}

miRNAs were determined using two-step RT-qPCR with RT-primer specific assay in combination with TaqMan probes: miR-143-5p (Assay ID: 463509_mat), miR-140-5p (Assay ID: 001187) miR-148a-5p (Assay ID: 473012_mat), miR-450a-5p (Assay ID: 462729_mat), miR-21-5p (Assay ID: 000397), miR-146b-5p (Assay ID: 002755), miR-342-3p (Assay ID: 002260), and miR-223-3p (Assay ID: 07896_mat) (Applied Biosystems; CA, USA). Each RTreaction used $1.5 \mu \mathrm{L}$ from the $14 \mu \mathrm{L}$ eluted RNA using the TaqMan MicroRNA Reverse Transcription Kit (Applied Biosystems; CA, USA). The RT reaction program and PCR cycling conditions were as we previously reported (Brianza-Padilla et al., 2016). miRNAs relative concentrations were normalized with $\mathrm{Ct}$ values of cel-miR-39, and values were calculated using $2^{-\Delta \Delta \mathrm{Ct}}$ and $2^{-\Delta \mathrm{Ct}}$ formulas. All Ct values for cel-miR-39 ranged from 20 to 22 cycles both for total plasma and for EVs RNA isolations.

\section{Statistical Analysis}

Data are presented as means and standard errors. Data were tested for normality and equal variances. Accordingly, differences between groups were assessed by unpaired t-test or MannWhitney U test $(\mathrm{p}<0.05)$ using the Graph Pad Prism software version 8.

\section{Results}

\section{Fructose exposure modified the release of microparticles in 3T3-L1 supernatant}

To determine whether fructose exposure modified the release of EVs, we quantified the total number of vesicles and their size by nanoparticle tracking analysis. Fructose exposure increased the total number of particles in the cell culture media by two-fold as compared to the control group ( $p=0.0001$ ) (Figure 1a). Although the mean size of EVs did not change between groups, we observed that fructose favored the release of vesicles below $200 \mathrm{~nm}$ (Figure 1b). Finally, the proteins characteristic of EVs such as CD63 and CD81 (tetraspanins enriched in late multivesicular bodies) (Kowal, Tkach \& Théry, 2014) and ANXA2 (calcium-dependent phospholipid-binding protein, as one of the most highly expressed proteins in EVs) (Valapala \& 
237

238

239

240

241

242

243

244

245

246

247

248

249

250

251

252

253

254

255

256

257

258

259

260

261

262

263

264

265

266

267

268

269

270

271

272

273

274

275

276

Vishwanatha, 2011) were determined by western blot. As expected, we found the presence of CD63, ANXA2, and CD81 in EVs of the 3T3-L1 cell supernatant (Figure 1c).

\section{Fructose modifies miRNA levels in supernatant EVs and 3T3-L1 cells}

In this study, we used a high concentration of fructose according to a previous study ( $\mathrm{Du}$ \& Heaney, 2012b) to evaluate the effects of fructose on miRNAs expression on EVs and cells, we exposed 3T3-L1 cells at $550 \mu \mathrm{M}$ of fructose for four days. We showed that exposure to 550 $\mu \mathrm{M}$ of fructose promoted high lipid accumulation compared to basal conditions $(p=0.0022)$ (Figure 1Sa). Moreover, Ppparg $(p=0.05)$, Glut4 $(p=0.05)$ and Cebpa $(p=0.05)$ expression were upregulated in both culture conditions compared to basal group (Figure 1Sb). Protein levels of PPAR $\gamma$ and GLUT4 increased in both control $(p=0.0140)$ and fructose exposure compared with basal group (Figure 1Sc). On the other hand, the differences in miRNA abundance is shown in Table 2, being miR-21-5p $>$ miR-143-5p $>$ miR-140-5p $>$ miR-146b-5p $>$ miR-342-3p $>$ miR223-3p $>$ miR-148a-5p $>$ miR-450a-5p in EVs from supernatans. EVs from fructose stimulated cells showed 3.8 times more miR-143-5p levels than the EVs derived from the 3T3-L1 cells of the control group ( $p=0.0286$ ) (Table 2 ). In contrast, we found a decrease of miR-223-3p levels (6-fold change) in EVs compared to the control cells $(p=0.0286)$ (Table 2). No differences were observed in miR-342-3p, miR-140-5p, miR-21-5p, miR-148a-5p, miR-450a-5p and miR-146b levels in EVs (Table 2). The differences in miRNA abundance in cell extracts are shown in Table 2 , being miR-21-5p $>\operatorname{miR}-146 b-5 p>\operatorname{miR}-140-5 p>\operatorname{miR}-143-5 p>\operatorname{miR}-342-3 p>\operatorname{miR}-223-3 p>$ miR-450a-5p $>$ miR-148a-5p. Fructose increased the expression of miR-223-3p $(p=0.0079)$, miR-143-5p ( $p=0.0179)$, miR-140-5p $(p=0.0079)$, miR-146b-5p $(p=0.0411)$ and miR-342-3p $(p=0.0159)$ at a cellular level (Table 2$)$, while the expressions of miR-21-5p, miR-148a-5p and miR-450a-5p did not change (Table 2).

\section{Fructose intake in water regulates metabolic parameters, miRNA levels in EVs plasma and rat adipose tissue}

In this study, we used a physiological concentration of fructose according to previous studies (Goran, Ulijaszek \& Ventura, 2013). We found that fructose exposure did not induce changes in total body weight and adipose tissue weight compared to the control group (Table 2) but increased the average of adipocyte area $(p=0.039)$ (Table 3$)$. The fructose in the drinking water increased the levels of glucose $(p=0.001)$, triglycerides $(p=0.001)$, and insulin $(p=0.007)$ in plasma (Table 3). Similarly, the HOMA-IR index was higher in the fructose group than the control group ( $p=0.007$ ) (Table 3$)$, as well as plasma adiponectin $(p=0.017)$, leptin $(p=0.012)$, and IL-1 $\beta(p=0.033)$ levels (Table 3$)$. In contrast, HDL-C levels were lower in the Fructose group than in the Control group $(p=0.042)$ (Table 3$)$.

To evaluate whether chronic fructose exposure would modify miRNA expression in adipose tissue and plasma-derived EVs, we fed rats with $20 \%$ of fructose in drinking water for eight weeks. To determine the effect of fructose exposure in the amount of plasma-derived EVs and its 
277 molecular cargo, we first determined the microparticle concentration by NTA analysis. The 278 number of particles were similar between both groups of animals (Figure 1d), while the mean 279 size of EVs increased in fructose-fed rats compared to the Control group ( $p=0.0117$ ) (Figure 1e). 280 Despite the similar levels of plasmatic EVs, we observed that high fructose intake induced 281 changes in miRNA content. The differences in miRNA abundance are shown in Table 4, being $282 \operatorname{miR}-223-3 p>\operatorname{miR}-21-5 p>\operatorname{miR}-140-5 p>\operatorname{miR}-143-5 p>\operatorname{miR}-146 b-5 p>\operatorname{miR}-342-3 p>\operatorname{miR}-$ $283450 a-5 p>$ miR-148a-5p in EVs from plasma. The miR-143-5p levels increased 10.14-fold in 284 EVs of the fructose rats $(p=0.0010)$ (Table 4$)$, while miR-223-3p ( -3.8 fold change) $(p=0.0220)$,

285

286

287

288

289

290

291

292

293

294

295

296

297

298

299

300

301

302

303

304

305

306

307

308

309

310

311

312

313

314

315

316 miR-342-3p (-9.47 fold change) $(p=0.0011)$, miR-140-5p ( -4.65 fold change) $(p=0.0129)$ and miR-146b-5p ( -4.27 fold change) $(p=0.0245)$ levels were reduced (Table 4$)$. We did not observe changes in miR-21-5p, miR148a-5p and miR-450a-5p levels in EVs (Table 4). Interestingly, we found a positive correlation between levels of miR-143-5p in EVs and triglycerides (rho= $0.7098 ; p=0.005$ ) and a negative correlation between levels of miR-143-5p in EVs and HDL-C $(\mathrm{rho}=-0.4577 ; p=0.0425)$ (Table S1). The levels of miR-342-3p in EVs negatively correlated with triglycerides (rho $=-0.3895 ; p=0.0448)$ (Table S1). The levels of miR-148a-5p in EVs positively correlated with glucose $(\mathrm{rho}=0.6657 ; p=0.0014)$ (Table S1). Finally, the levels of miR-146b-5p in EVs negatively correlated with leptin (rho= $-0.4617 ; p=0.0405$ ) (Table S1). The differences in miRNA abundance in adipose tissue is shown in Table 4, being miR-21-5p $>$ miR$223-3 p>\operatorname{miR}-450 a-5 p>\operatorname{miR}-140-5 p>\operatorname{miR}-146 b-5 p>\operatorname{miR}-143-5 p>\operatorname{miR}-342-3 p>$ miR-148a$5 \mathrm{p}$. In the adipose tissue, we found that fructose exposure induced an increase in miR-143-5p expression $(p=0.0143)$ (Table 4$)$, whereas miR-223-3p $(p=0.0462)$ and miR-342-3p $(p=0.0320)$ expression were reduced in the Fructose group (Table 4). We did not find differences in the expression of miR-140-5p, miR-21-5p, miR-148a-5p, miR-450a-5p and miR-146b-5p (Table 4).

\section{Pathway enrichment of adipocyte miRNAs}

To predict the cellular pathways targeted during fructose exposure, we used DIANAmiRPath for identification of putative miRNA targets. The analysis Kyoto Encyclopedia of Genes and Genomes (KEGG) pathway from miRPath revealed that miRNAs altered by fructose exposure target genes involved in TGF- $\beta$ and mTOR signaling pathways, each signaling pathway have putative targets of 25 genes (Figure 2S, Figure $3 \mathrm{~S}$ and Table 4S).

\section{Discussion}

In our study, we found that high fructose exposure modified the abundance of some adipocyte-related miRNAs in EVs derived from 3T3-L1cells supernatants and rat plasma. In particular, fructose exposure increased the levels of miR-143-5p and decreased miR-223-3p levels in EVs. In rat plasma, fructose promoted the production of large EVs size and increased the levels of miR-143-5p in EVs, and reduced miR-223-3p, miR-140-5p, and miR-342-3p. In this report, we showed that $20 \%(\mathrm{w} / \mathrm{v})$ of fructose in drinking water for eight weeks did not change body weight but increased in the average of adipocyte area without changing in the total 
317 adipose tissue weight. These results, together with the increase in glucose, insulin, and 318 triglyceride levels and a decrease in HDL-C levels, suggest the development of the metabolic 319 syndrome. Similar findings have been found in a previous report (Zubiría et al., 2016a).

320

321

322

323

324

325

326

327

328

329

330

331

332

333

334

335

336

337

338

339

340

341

342

343

344

345

346

347

348

349

350

351

352

353

354

355

356

357

358

359

The dose of fructose was chosen to resemble the intake of the highest consumers of added sugars in the USA which represents $20-25 \%$ of daily caloric intake (Goran, Ulijaszek \& Ventura, 2013). Moreover, the concentration of fructose in beverages often vary between $10-30 \%(\mathrm{w} / \mathrm{v})$, and the duration of these experiments is also variable (Toop \& Gentili, 2016). Therefore, there is not a consensus about a particular experimental concentration of fructose intake. Moreover, studies in healthy humans showed that the intake of a fructose $20 \%(\mathrm{w} / \mathrm{v})$ solution increased plasma triacylglycerol and glucose concentrations (Faeh et al., 2005; Lê et al., 2006). Based in this information, we chose a concentration of fructose $20 \%$ in drinking water to assure the induction of metabolic disorders. The increase of the average of adipocyte area suggest that the exposure of fructose for eight weeks induces hypertrophy of the adipocytes. This effect may be explained because the fructose fed rats developed hyperleptinemia. It has been reported that the hyperleptinemia and leptin resistance in adipose tissue induced by chronic fructose intake favors adipocyte hypertrophy (Sangüesa et al., 2018). Furthermore, hypertrophic adipocytes may release paracrine factors, including EVs, which promote the recruitment of preadipocytes and induce their differentiation into mature adipocytes.

Current studies had demonstrated that EVs are endocrine signals that regulate several cellular processes. Several studies found that adipocytes can release EVs under different stimuli (Connolly et al., 2015; Durcin et al., 2017). For example, it has been observed that 3T3-L1 cells release EVs through the stimulation of cAMP/Epac-dependent, and this release is augmented by a combination of $\mathrm{Ca} 2+$ and ATP (Komai et al., 2014). Moreover, the long-chain omega-3 fatty acid docosahexaenoic acid promotes the increase in the release of EVs in 3T3-L1 cells (Declercq, D'Eon \& McLeod, 2015). Our findings showed that fructose exposure increased the release of EVs from supernatants of 3T3-L1 cells, but the amount of EVs did not change in the plasma of fructose-fed rats. We think that the increased amount of released EVs from cell cultures could result from the direct to exposure to high fructose concentration $(550 \mu \mathrm{M})$. In contrast, some studies have reported that after the ingestion of sweetened drinks, the systemic concentration of fructose is of $363.4 \mu \mathrm{M}$ (Le et al., 2012). Similarly, rats that had access to a solution rich in fructose $(2 \mathrm{~g} / \mathrm{kg})$ displayed a concentration of $146 \mu \mathrm{M}$ of fructose in peripheral blood (Sugimoto et al., 2010). Therefore, it is possible that adipose tissue in vivo is exposed to lower concentrations of fructose. Also, the effect of fructose could be obscured in plasma-derived EVs because they correspond a complex mixture from different cell types. In the future it would be necessary to specifically isolate EVs from adipose tissue.

In a recent study, it was shown that adipocytes release two types of EVs: small EVs (below $100 \mathrm{~nm}$ ) and large EVs (100-200 nm) (Durcin et al., 2017). In this study, we found that fructose exposure promoted the release of EVs between 100-200 nm. Thus, our results suggest that fructose induces the release of large EVs in 3T3-L1 cells, which may be enriched in adipogenic signaling proteins and mitochondrial markers (Durcin et al., 2017). Further studies are needed to elucidate whether fructose promotes the release of EVs of adipose tissue origin in rat plasma that has a metabolic role. On the other hand, currents findings have demonstrated that the RNAbinding proteins (RBPs) are involved in sorting the miRNAs process into EVs (Groot \& Lee,

Peer) reviewing PDF | (2020:10:53327:1:0:CHECK 2 Mar 2021) 
360

361

362

363

364

365

366

367

368

369

370

371

372

373

374

375

376

377

378

379

380

381

382

383

384

385

386

387

388

389

390

391

392

393

394

395

396

397

398

399

2020). Among these proteins, it was found the Y-box Binding Protein 1 promotes the sorting of miR-223-3p into EVs from HEK293T cells (Shurtleff et al., 2016). Because the fructose exposure modified levels of miRNAs in EVs from adipocytes, likely fructose regulates RBPs involved in the sorting process into EVs. However, more studies are needed to elucidate the effect of fructose on the modulation of miRNAs levels in EVs by regulation of RBPs.

In our results, we found that fructose increased miR-143-5p expression from EVs of both 3T3-L1 cells and rat plasma as well as from whole tissue and cells extracts (Figure 2).The miR143 is conserved between rats and humans, and several studies show an important role for this miRNA in lipid metabolism, adipogenesis, and insulin resistance. Similarly, augmented levels of miR-143-5p expression were reported in vitro models of adipogenesis (Esau et al., 2004). Also, this miRNA induces adipogenesis by promoting triglycerides synthesis (Wang et al., 2011) and accelerates lipid accumulation (Xie, Lim \& Lodish, 2009). We showed that fructose induced an elevation of the levels of miR-143-5p in EVs derived from both 3T3-L1 cells and rat plasma, which supports an active metabolic role for EVs in metabolic processes. In agreement with this notion, we found a positive correlation between levels of miR-143-5p in EVs of fructose-fed rats and triglycerides and a negative correlation with HDL-C. Moreover, obese subjects and healthy subjects with a high-fat diet also presented high levels of miR-143-5p in the total plasma (Quintanilha et al., 2019; Ramzan et al., 2019). Recent studies showed that miR-143-5p remains unchanged in the total plasma of sucrose-fed mice for 20 weeks (Hanousková et al., 2019) and sucrose-fed rats for 4 weeks (Yerlikaya \& Mehmet, 2019). Conversely, we also found that fructose-fed rats for 4 weeks increase the levels of miR-143-5p in total plasma $(p=0.031)$ (Table S3) together with an elevation of triglycerides $(\mathrm{p}=0.005)$ (Table S2). The fructose exposure increased ten-fold the abundance of miR-143-5p in EVs. Our data supports the notion that fructose may induce lipid metabolism by endocrine mechanisms, including the release of EVs containing miR-143-5p.

Our study showed that the exposure to fructose decreases in miR-223-3p levels in EVs from both cell supernatants and rat plasma (Figure 2). Opposite results were found in EVs of sucrosefed rats for a longer period of time (six months) (Brianza-Padilla et al., 2016). This difference could be due to the source of fructose (sucrose). Previous reports showed that sucrose and the mix of monosaccharides (fructose+glucose) have different effects on lipid and glucose metabolism in rats and humans. Therefore, the low miR-223-3p levels in EVs of rat plasma could be an effect of the exposition to only fructose (Sánchez-Lozada et al., 2010; Sheludiakova, Rooney \& Boakes, 2012; Evans et al., 2017). Therefore, the low miR-223-3p levels in EVs of rat plasma could be an effect of the exposition to only fructose. The miR-223 is a miRNA conserved between rats and humans. Moreover, miR-223-3p is reduced in total plasma of obese subjects (Kilic et al., 2015; Wen, Qiao \& Wang, 2015) and T2DM patients (Zampetaki et al., 2010). The function of miR-223-3p has been related to the inflammatory response and adipocyte differentiation. Studies had demonstrated that miR-223-3p promotes adipogenesis in mesenchymal stem cells (Guan et al., 2015b) and human adipocytes (Liu et al., 2010). Our study showed that the exposure to fructose augmented miR-223-3p expression in 3T3-L1 cells, while it 
400 was reduced in rat adipose tissue (Figure 2). The differential miRNA expression between cell 401 culture and tissue could be due to the cell complexity of adipose tissue (Kanneganti \& Dixit, 402 2012). For example, in visceral adipose tissue from obese patients, the miR-223-3p was 403 upregulated specifically in the stromal vascular cells, while in adipocytes, this miRNA was 404 unchanged (Deiuliis et al., 2016). Additionally, the upregulation of miR-223-3p leads to the 405 downregulation of GLUT4 in human adipocytes (Chuang et al., 2015). On the other hand, in 406 mice adipose tissue, miR-223-3p suppresses pro-inflammatory activation of macrophages 407 (Zhuang et al., 2012) and regulates the production of NLRP3 and IL-1 $\beta$ (Bauernfeind et al., 408 2012). Although a role for miR-223-3p in adipogenesis is suggested by its increase in 3T3-L1 cells treated with fructose. In whole adipose tissue, fructose may induce an IL- $1 \beta$-mediated

410

411

412

413

414

415

416

417

418

419

420

421

422

423

424

425

426

427

428

429

430

431

432

433

434

435

436

437

438

439 inflammatory response due to the downregulation of miR-223-3p. However, additional studies are necessary to elucidate whether systemic and local downregulation of miR-223-3p in EVs participates in systemic IL-1 $\beta$ production.

Our study showed that fructose reduced miR-342-3p levels in EVs from rat plasma (Figure 2). A similar effect has been observed in total plasma of obese children (Khalyfa et al., 2016) and insulin-resistant subjects (Wang et al., 2015a; Masotti et al., 2017). The miR-342-3p is a miRNA conserved between rats and humans and is implicated in lipid metabolism and adipogenesis. In human adipose-derived mesenchymal stem cells, miR-342-3p enhances adipogenesis (Wang et al., 2015b). Also, in non-adipocyte cells, it was found that this miRNA reduces lipogenesis by inhibiting the expression of SREBP ( $\mathrm{Li}$ et al., 2013). Interestingly, we found a negative correlation between levels of miR-342-3p in EVs from fructose-fed rats and triglycerides. Despite the abundance of miR-342-3p in EVs is medium, the fructose exposure induced a decrease of nine-fold of this miRNA. Therefore, our findings add to the notion that fructose may induce lipogenesis by the reduction of this miRNA in EVs and tissue. Moreover, we found that fructose increased miR-342-3p expression in 3T3-L1 cells and reduced in rat adipose tissue (Figure 2). Because our findings show that fructose exposure is related to an increase of miR$342-3 p$ in 3T3-L1 cells and that chronic fructose intake in rats decreases miR-342-3p in adipose tissue, and EVs may be due to that this miRNA is more expressed in adipocytes than the stromal vascular fraction from adipose tissue (Oger et al., 2014), so that other cell types contribute to this miRNA secretion.

In our results, fructose reduced the levels of miR-140-5p in EVs of rat plasma. Elsewhere a similar trend was found in the total plasma of obese patients (Wang et al., 2015a). However, other studies in morbidly obese subjects and diabetic subjects showed high levels of miR-140-5p in total plasma (Ortega et al., 2013, 2014). Moreover, we found that fructose increased miR-140$5 \mathrm{p}$ expression in 3T3-L1 cells, supporting the notion that it is related to adipogenesis ( $\mathrm{Li}$ et al., 2017). The abundance of miR-140-5p is medium in EVs, adipocytes, and adipose tissue and fructose exposure induced a reduction of the abundance of 4-fold of this miRNA in EVs from rat plasma. Thus, our results suggest that the miR-140-5p may be involved with metabolic alterations developed in fructose-fed rats. However, future experiments should document longer exposures to fructose to determine if chronic stimulation modifies levels in EVs. 
440

441

442

443

444

445

446

447

448

449

450

451

452

453

454

455

456

457

458

459

460

461

462

463

464

465

466

467

468

469

470

471

472

473

474

475

476

477

478

479

This study showed that fructose exposure reduces the levels of miR-146b-5p in EVs of rat plasma. The miR-146b is a miRNA conserved between rats and humans. A study in obese children and adult T2DM showed high miR-146b-5p levels in the total plasma, which was found that participated in the suppression of high concentration glucose-induced pancreatic insulin secretion (Cui et al., 2018; Mohany et al., 2020). Interestingly, we found a negative correlation between the levels of miR-146b-5p in EVs and leptin in plasma. Noteworthy, the leptin mRNA is a target of miR-146b-5p in breast adipose tissue (Al-Khalaf et al., 2017). Our findings showed that the abundance of miR-146b-5p in EVs is medium, and the fructose exposure reduced 4-fold of this miRNA in EVs. If this reduction may participate in the hyperleptinemia found in fructosefed rats should be further investigated. On the other hand, we found that fructose increases miR$146 b-5 p$ expression only in 3T3-L1 cells. The miR-146b-5p is a miRNAs related to inflammatory response and adipogenesis. In this line, a previous study showed that miR-146b-5p induces adipogenesis in human preadipocytes (Chen et al., 2014b). The same report found that the expression of this miRNA increases in adipose tissue of diet-induced obesity mice (Chen et al., 2014b). Moreover, TNF- $\alpha$ treatment induces miR-146b-5p expression in adipocytes. Also, it has been demonstrated that this miRNA regulates glucose homeostasis in porcine primary preadipocytes by targeting IRS1 (Zhu et al., 2018). Therefore, our results on 3T3-L1 cells could indicate that fructose may promote adipogenesis by increasing miR-146b-5p expression.

The miR-450a-5p, miR-148a-5p and miR-21-5p participate in adipocyte differentiation. For example, Zhang and collaborators showed that miR-450a-5p induces adipogenesis through the transfer of this miRNA by EVs in adipose tissue-derived stem cells (Zhang et al., 2017).

However, we found that the abundance of miR-450a-5p in EVs is low, and we did not find changes in this miRNA in both cells and rats. However, we found that fructose-fed rats for 4 weeks increase the levels of miR-450a-5p in total plasma (Table S3). A recent study showed that the up-regulation of this miRNA improves insulin resistance in non-adipocyte cells (Wei, Meng \& Zhang, 2020). On the other hand, we showed that the abundance of miR-21-5p in EVs is high; however, we did not find changes in this miRNA in both cells and rats. It has been demonstrated that the presence of miR-21-5p is involved in the proliferation and differentiation of adipocyte precursors (Jeong Kim et al., 2009; Kim et al., 2012). Besides, miR-148a-5p is highly expressed in human MSC-derived adipose tissue during adipogenesis (Shi et al., 2015b). We found that the abundance of miR-148a-5p is low in EVs, and fructose exposure did not change the expression of this miRNA, both in cells and rats. However, we found a positive correlation between the levels of miR-148a in EVs and glucose. This finding suggests that miR$148 \mathrm{a}-5 \mathrm{p}$ is associated with alterations in glucose metabolism. In addition, our findings suggest that fructose may also use other mechanisms that do not involve changes in miR-450a-5p, miR148a-5p, and miR-21-5p expression.

Several miRNAs have been previously associated to regulate metabolic processes in humans and murine models. Through miRPath software, we predicted signaling pathways that could be affected in a combinatorial manner by exposure to fructose. Interestingly, miRNAs that change by fructose exposure were predicted to target 19 genes in the TGF- $\beta$ signaling pathway (Figure 
480 1S) (Table 4S). In EVs from rat plasma, the decrease levels of miR-140-5p, miR-146b-5p, miR$481223-3 p$ and miR-342-3p could favor the TGF- $\beta$ signaling pathway by fructose exposure (Figure 482 1S) (Table 4S). Recent studies have reported that the activation of TGF- $\beta$ signaling inhibits 483 adipocyte differentiation (Luo et al., 2019) and is involved in lipid accumulation in the liver (Qin 484 et al., 2018). Therefore, fructose could favor lipid accumulation by downregulating these EVs485 associated miRNAs. The mTOR signaling pathway could also be regulating the selected

486

487

488

489

490

491

492

493

494

495

496

497

498

499

500

501

502

503

504

505

506

507

508

509

510

511

512

513

514

515

516

517

518

519

520 miRNAs (Figure 2S). The miRPath analysis predicted to target 21 genes in the mTOR signaling pathway (Table 4S). Studies indicate that the mTOR pathway is involved in several cellular processes, including proliferation and glucose and lipid metabolism (Mao \& Zhang, 2018; Sangüesa et al., 2019). Moreover, a fructose-dependent increase in mTORC1 activity drives translation of pro-inflammatory cytokines (Jones et al., 2021). Therefore, fructose exposure could modulate these signal pathways involved in physiology adipose tissue by regulating selected miRNAs.

\section{Conclusions}

Fructose exposure promotes an increase in the release of EVs with increased levels of miR143-5p and decreased levels of miR-223-3p. Also, fructose induces an increase of miR-143-5p, miR-223-3p, miR-140-5p, miR-342-3p and miR-146b-5p in adipocytes. Similarly, in rats, the high fructose intake induces an increase of miR-143-5p and a decrease of miR-223-3p and miR$342-3 p$ in both EVs and adipose tissue. Finally, the in vitro and in vivo models show that fructose may modify the way miRNAs are shipped into EVs. It would be important in the future to evaluate whether the miR-143-5p and miR-223-3p in EVs could be potential biomarkers of fructose exposure in humans.

\section{Acknowledgments}

The authors are grateful to Hugo Villamil-Ramirez from the UGEPAS-Facultad de Química, Universidad Nacional Autónoma de México (UNAM)/Instituto Nacional de Medicina Genómica (INMEGEN), Mexico City 14610, Mexico, for providing laboratory technical advisory.

\section{References}

Ahn J, Lee H, Jung CH, Jeon T Il, Ha TY. 2013. MicroRNA-146b promotes adipogenesis by suppressing the SIRT1-FOXO1 cascade. EMBO molecular medicine 5:1602-12. DOI: 10.1002/emmm.201302647.

Al-Khalaf HH, Amir M, Al-Mohanna F, Tulbah A, Al-Sayed A, Aboussekhra A. 2017. Obesity and p16INK4A Downregulation Activate Breast Adipocytes and Promote Their Protumorigenicity. Molecular and cellular biology 37. DOI: 10.1128/MCB.00101-17.

Bauernfeind F, Rieger A, Schildberg FA, Knolle PA, Schmid-Burgk JL, Hornung V. 2012. NLRP3 Inflammasome Activity Is Negatively Controlled by miR-223. The Journal of Immunology 189:4175-4181. DOI: 10.4049/jimmunol.1201516. 
521

522

523

524

525

526

527

528

529

530

531

532

533

534

535

536

537

538

539

540

541

542

543

544

545

546

547

548

549

550

551

552

553

554

555

556

557

558

559

560

561

562

563

564

565

566

Brianza-Padilla M, Carbó R, Arana JC, Vázquez-Palacios G, Ballinas-Verdugo MA, CardosoSaldaña GC, Palacio AG, Juárez-Vicuña Y, Sánchez F, Martínez-Martínez E, Huang F, Sánchez-Muñoz F, Bojalil R, a Y, S\&\#xe1, nchez F, Mart\&\#xed, nez-Mart\&\#xed, nez E, Huang F, S\&\#xe1, nchez-Mu\&\#xf1, oz F, Bojalil R. 2016. Inflammation Related MicroRNAs Are Modulated in Total Plasma and in Extracellular Vesicles from Rats with Chronic Ingestion of Sucrose. BioMed Research International 2016:1-7. DOI: $10.1155 / 2016 / 2489479$.

Chartoumpekis D V., Zaravinos A, Ziros PG, Iskrenova RP, Psyrogiannis AI, Kyriazopoulou VE, Habeos IG. 2012. Differential Expression of MicroRNAs in Adipose Tissue after Long-Term High-Fat Diet-Induced Obesity in Mice. PLoS ONE 7:e34872. DOI: 10.1371/journal.pone.0034872.

Chen L, Dai Y-M, Ji C-B, Yang L, Shi C-M, Xu G-F, Pang L-X, Huang F-Y, Zhang C-M, Guo X-R. 2014a. MiR-146b is a regulator of human visceral preadipocyte proliferation and differentiation and its expression is altered in human obesity. Molecular and Cellular Endocrinology 393:65-74. DOI: 10.1016/j.mce.2014.05.022.

Chen L, Dai Y-M, Ji C-B, Yang L, Shi C-M, Xu G-F, Pang L-X, Huang F-Y, Zhang C-M, Guo X-R. 2014b. MiR-146b is a regulator of human visceral preadipocyte proliferation and differentiation and its expression is altered in human obesity. Molecular and Cellular Endocrinology 393:65-74. DOI: 10.1016/J.MCE.2014.05.022.

Chuang TY, Wu HL, Chen CC, Gamboa GM, Layman LC, Diamond MP, Azziz R, Chen YH. 2015. MicroRNA-223 expression is upregulated in insulin resistant human adipose tissue. Journal of Diabetes Research 2015:2-10. DOI: 10.1155/2015/943659.

Collares CV, Evangelista AF, Xavier DJ, Rassi DM, Arns T, Foss-Freitas MC, Foss MC, Puthier D, Sakamoto-Hojo ET, Passos GA, Donadi EA. 2013. Identifying common and specific microRNAs expressed in peripheral blood mononuclear cell of type 1 , type 2 , and gestational diabetes mellitus patients. BMC Research Notes 6. DOI: 10.1186/1756-0500-6491.

Connolly KD, Guschina IA, Yeung V, Clayton A, Draman MS, Von Ruhland C, Ludgate M, James PE, Rees DA. 2015. Characterisation of adipocyte-derived extracellular vesicles released pre- and post-adipogenesis. Journal of Extracellular Vesicles 4:29159. DOI: 10.3402/jev.v4.29159.

Cui X, You L, Zhu L, Wang X, Zhou Y, Li Y, Wen J, Xia Y, Wang X, Ji C, Guo X. 2018. Change in circulating microRNA profile of obese children indicates future risk of adult diabetes. Metabolism: Clinical and Experimental 78:95-105. DOI: 10.1016/j.metabol.2017.09.006.

Declercq V, D'Eon B, McLeod RS. 2015. Fatty acids increase adiponectin secretion through both classical and exosome pathways. Biochimica et Biophysica Acta-Molecular and Cell Biology of Lipids 1851:1123-1133. DOI: 10.1016/j.bbalip.2015.04.005.

Deiuliis JA, Syed R, Duggineni D, Rutsky J, Rengasamy P, Zhang J, Huang K, Needleman B, Mikami D, Perry K, Hazey J, Rajagopalan S. 2016. Visceral adipose MicroRNA 223 is upregulated in human and murine obesity and modulates the inflammatory phenotype of macrophages. PLoS ONE 11. DOI: 10.1371/journal.pone.0165962.

Du L, Heaney AP. 2012a. Regulation of Adipose Differentiation by Fructose and GluT5. Molecular Endocrinology 26:1773-1782. DOI: 10.1210/me.2012-1122.

Du L, Heaney AP. 2012b. Regulation of Adipose Differentiation by Fructose and GluT5. Molecular Endocrinology 26:1773-1782. DOI: 10.1210/me.2012-1122.

Peer] reviewing PDF | (2020:10:53327:1:0:CHECK 2 Mar 2021) 
567

568

569

570

571

572

573

574

575

576

577

578

579

580

581

582

583

584

585

586

587

588

589

590

591

592

593

594

595

596

597

598

599

600

601

602

603

604

605

606

607

608

609

610

611

612

Durcin M, Fleury A, Taillebois E, Hilairet G, Krupova Z, Henry C, Truchet S, Trötzmüller M, Köfeler H, Mabilleau G, Hue O, Andriantsitohaina R, Martin P, Lay S Le. 2017. Characterisation of adipocyte-derived extracellular vesicle subtypes identifies distinct protein and lipid signatures for large and small extracellular vesicles. Journal of Extracellular Vesicles 6:1305677. DOI: 10.1080/20013078.2017.1305677.

Enderle D, Spiel A, Coticchia CM, Berghoff E, Mueller R, Schlumpberger M, SprengerHaussels M, Shaffer JM, Lader E, Skog J, Noerholm M. 2015. Characterization of RNA from Exosomes and Other Extracellular Vesicles Isolated by a Novel Spin Column-Based Method. PLOS ONE 10:e0136133. DOI: 10.1371/journal.pone.0136133.

Engin AB. 2017. MicroRNA and adipogenesis. In: Advances in Experimental Medicine and Biology. Springer New York LLC, 489-509. DOI: 10.1007/978-3-319-48382-5_21.

Esau C, Kang X, Peralta E, Hanson E, Marcusson EG, Ravichandran L V., Sun Y, Koo S, Perera RJ, Jain R, Dean NM, Freier SM, Bennett CF, Lollo B, Griffey R. 2004. MicroRNA-143 Regulates Adipocyte Differentiation. Journal of Biological Chemistry 279:52361-52365. DOI: $10.1074 /$ jbc.C400438200.

Evans RA, Frese M, Romero J, Cunningham JH, Mills KE. 2017. Fructose replacement of glucose or sucrose in food or beverages lowers postprandial glucose and insulin without raising triglycerides: a systematic review and meta-analysis. The American Journal of Clinical Nutrition 106:506-518. DOI: 10.3945/ajcn.116.145151.

Faeh D, Minehira K, Schwarz JM, Periasami R, Seongsu P, Tappy L. 2005. Effect of fructose overfeeding and fish oil administration on hepatic de novo lipogenesis and insulin sensitivity in healthy men. Diabetes 54:1907-1913. DOI: 10.2337/diabetes.54.7.1907.

Gebert LFR, MacRae IJ. 2019. Regulation of microRNA function in animals. Nature Reviews Molecular Cell Biology 20:21-37. DOI: 10.1038/s41580-018-0045-7.

Goran MI, Ulijaszek SJ, Ventura EE. 2013. High fructose corn syrup and diabetes prevalence: A global perspective. Global Public Health 8:55-64. DOI: 10.1080/17441692.2012.736257.

Groot M, Lee H. 2020. Sorting Mechanisms for MicroRNAs into Extracellular Vesicles and Their Associated Diseases. Cells 9:1044. DOI: 10.3390/cells9041044.

Guan X, Gao Y, Zhou J, Wang J, Zheng F, Guo F, Chang A, Li X, Wang B. 2015a. miR-223 Regulates Adipogenic and Osteogenic Differentiation of Mesenchymal Stem Cells Through a C/EBPs/miR-223/FGFR2 Regulatory Feedback Loop. STEM CELLS 33:1589-1600. DOI: 10.1002/stem.1947.

Guan X, Gao Y, Zhou J, Wang J, Zheng F, Guo F, Chang A, Li X, Wang B. 2015b. miR-223 Regulates Adipogenic and Osteogenic Differentiation of Mesenchymal Stem Cells Through a C/EBPs/miR-223/FGFR2 Regulatory Feedback Loop. STEM CELLS 33:1589-1600. DOI: 10.1002/stem.1947.

Guglielmi V, D’Adamo M, Menghini R, Cardellini M, Gentileschi P, Federici M, Sbraccia P. 2017. MicroRNA 21 is up-regulated in adipose tissue of obese diabetic subjects. Nutrition and Healthy Aging 4:141-145. DOI: 10.3233/NHA-160020.

Hanousková B, Neprašová B, Skálová L, Maletínská L, Zemanová K, Ambrož M, Matoušková P. 2019. High-fructose drinks affect microRNAs expression differently in lean and obese mice. Journal of Nutritional Biochemistry 68:42-50. DOI: 10.1016/j.jnutbio.2019.03.001.

Hernández-Díazcouder A, Romero-Nava R, Carbó R, Sánchez-Lozada LG, Sánchez-Muñoz F. 2019. High Fructose Intake and Adipogenesis. International Journal of Molecular Sciences 20:2787. DOI: 10.3390/ijms20112787.

Hörbelt T, Knebel B, Fahlbusch P, Barbosa D, de Wiza DH, Van de Velde F, Van Nieuwenhove

Peer] reviewing PDF | (2020:10:53327:1:0:CHECK 2 Mar 2021) 
613

614

615

616

617

618

619

620

621

622

623

624

625

626

627

628

629

630

631

632

633

634

635

636

637

638

639

640

641

642

643

644

645

646

647

648

649

650

651

652

653

654

655

656

657

658

Y, Lapauw B, Thoresen GH, Al-Hasani H, Müller-Wieland D, Ouwens DM, Kotzka J. 2019. The adipokine sFRP4 induces insulin resistance and lipogenesis in the liver. Biochimica et Biophysica Acta - Molecular Basis of Disease 1865:2671-2684. DOI: 10.1016/j.bbadis.2019.07.008.

Huang-Doran I, Zhang C-Y, Vidal-Puig A. 2017. Extracellular Vesicles: Novel Mediators of Cell Communication In Metabolic Disease. Trends in Endocrinology \& Metabolism 28:318. DOI: 10.1016/j.tem.2016.10.003.

Jeong Kim Y, Jin Hwang S, Chan Bae Y, Sup Jung J. 2009. MiR-21 regulates adipogenic differentiation through the modulation of TGF-?? signaling in mesenchymal stem cells derived from human adipose tissue. Stem Cells 27:3093-3102. DOI: 10.1002/stem.235.

Jones N, Blagih J, Zani F, Rees A, Hill DG, Jenkins BJ, Bull CJ, Moreira D, Bantan AIM, Cronin JG, Avancini D, Jones GW, Finlay DK, Vousden KH, Vincent EE, Thornton CA. 2021. Fructose reprogrammes glutamine-dependent oxidative metabolism to support LPSinduced inflammation. Nature communications 12:1209. DOI: 10.1038/s41467-021-214614.

Jordan SD, Krüger M, Willmes DM, Redemann N, Wunderlich FT, Brönneke HS, Merkwirth C, Kashkar H, Olkkonen VM, Böttger T, Braun T, Seibler J, Brüning JC. 2011. Obesityinduced overexpression of miRNA-143 inhibits insulin-stimulated AKT activation and impairs glucose metabolism. Nature Cell Biology 13:434-448. DOI: 10.1038/ncb2211.

Kanneganti TD, Dixit VD. 2012. Immunological complications of obesity. Nature Immunology 13:707-712. DOI: 10.1038/ni.2343.

Khalyfa A, Kheirandish-Gozal L, Bhattacharjee R, Khalyfa AA, Gozal D. 2016. Circulating microRNAs as potential biomarkers of endothelial dysfunction in obese children. Chest 149:786-800. DOI: 10.1378/chest.15-0799.

Kilic ID, Dodurga Y, Uludag B, Alihanoglu YI, Yildiz BS, Enli Y, Secme M, Bostanci HE. 2015. MicroRNA -143 and -223 in obesity. Gene 560:140-142. DOI: 10.1016/j.gene.2015.01.048.

Kim YJ, Hwang SH, Cho HH, Shin KK, Bae YC, Jung JS. 2012. MicroRNA 21 regulates the proliferation of human adipose tissue-derived mesenchymal stem cells and high-fat dietinduced obesity alters microRNA 21 expression in white adipose tissues. Journal of Cellular Physiology 227:183-193. DOI: 10.1002/jcp.22716.

Komai AM, Brännmark C, Musovic S, Olofsson CS. 2014. PKA-independent cAMP stimulation of white adipocyte exocytosis and adipokine secretion: Modulations by $\mathrm{Ca} 2+$ and ATP. Journal of Physiology 592:5169-5186. DOI: 10.1113/jphysiol.2014.280388.

Kowal J, Tkach M, Théry C. 2014. Biogenesis and secretion of exosomes. Current Opinion in Cell Biology 29:116-125. DOI: 10.1016/j.ceb.2014.05.004.

Lê KA, Faeh D, Stettler R, Ith M, Kreis R, Vermathen P, Boesch C, Ravussin E, Tappy L. 2006. A 4-wk high-fructose diet alters lipid metabolism without affecting insulin sensitivity or ectopic lipids in healthy humans. American Journal of Clinical Nutrition 84:1374-1379. DOI: $10.1093 / \mathrm{ajcn} / 84.6 .1374$.

Le MT, Frye RF, Rivard CJ, Cheng J, McFann KK, Segal MS, Johnson RJ, Johnson JA. 2012. Effects of high-fructose corn syrup and sucrose on the pharmacokinetics of fructose and acute metabolic and hemodynamic responses in healthy subjects. Metabolism: Clinical and Experimental 61:641-651. DOI: 10.1016/j.metabol.2011.09.013.

Legeza B, Marcolongo P, Gamberucci A, Varga V, Bánhegyi G, Benedetti A, Odermatt A. 2017. Fructose, Glucocorticoids and Adipose Tissue: Implications for the Metabolic Syndrome.

Peer) reviewing PDF | (2020:10:53327:1:0:CHECK 2 Mar 2021) 
659

660

661

662

663

664

665

666

667

668

669

670

671

672

673

674

675

676

677

678

679

680

681

682

683

684

685

686

687

688

689

690

691

692

693

694

695

696

697

698

699

700

701

702

703

704

Nutrients 9:426. DOI: 10.3390/nu9050426.

Li X, Chen YT, Josson S, Mukhopadhyay NK, Kim J, Freeman MR, Huang WC. 2013. MicroRNA-185 and 342 Inhibit Tumorigenicity and Induce Apoptosis through Blockade of the SREBP Metabolic Pathway in Prostate Cancer Cells. PLoS ONE 8. DOI: 10.1371/journal.pone.0070987.

Li Z, Jin C, Chen S, Zheng Y, Huang Y, Jia L, Ge W, Zhou Y. 2017. Long non-coding RNA MEG3 inhibits adipogenesis and promotes osteogenesis of human adipose-derived mesenchymal stem cells via miR-140-5p. Molecular and Cellular Biochemistry 433:51-60. DOI: $10.1007 / \mathrm{s} 11010-017-3015-\mathrm{z}$.

Li T, Morgan MJ, Choksi S, Zhang Y, Kim Y-S, Liu Z. 2010. MicroRNAs modulate the noncanonical transcription factor $\mathrm{NF}-\kappa \mathrm{B}$ pathway by regulating expression of the kinase IKK $\alpha$ during macrophage differentiation. Nature Immunology 11:799-805. DOI: 10.1038/ni. 1918.

Liu B, Qin L, Liu A, Uchiyama S, Ueno T, Li X, Wang P. 2010. Prevalence of the equolproducer phenotype and its relationship with dietary isoflavone and serum lipids in healthy Chinese adults. Journal of epidemiology 20:377-84. DOI: 10.2188/jea.je20090185.

Lu H, Buchan RJ, Cook SA. 2010. MicroRNA-223 regulates Glut4 expression and cardiomyocyte glucose metabolism. Cardiovascular Research 86:410-420. DOI: 10.1093/cvr/cvq010.

Luo H, Guo Y, Liu Y, Wang Y, Zheng R, Ban Y, Peng L, Yuan Q, Liu W. 2019. Growth differentiation factor 11 inhibits adipogenic differentiation by activating TGF-beta/Smad signalling pathway. Cell Proliferation 52. DOI: 10.1111/cpr.12631.

Mao Z, Zhang W. 2018. Role of mTOR in glucose and lipid metabolism. International Journal of Molecular Sciences 19. DOI: 10.3390/ijms19072043.

Masotti A, Baldassarre A, Fabrizi M, Olivero G, Loreti MC, Giammaria P, Veronelli P, Graziani MP, Manco M. 2017. Oral glucose tolerance test unravels circulating miRNAs associated with insulin resistance in obese preschoolers. Pediatric Obesity 12:229-238. DOI: 10.1111/ijpo.12133.

Matthews DR, Hosker JP, Rudenski AS, Naylor BA, Treacher DF, Turner RC. 1985. Homeostasis model assessment: insulin resistance and beta-cell function from fasting plasma glucose and insulin concentrations in man. Diabetologia 28:412-9. DOI: 10.1007/bf00280883.

Mohany KM, Al Rugaie O, Al-Wutayd O, Al-Nafeesah A, Saleem TH. 2020. Association between circulating microRNAs $486,146 \mathrm{~b}$ and $15 \mathrm{~b}$ and serum betatrophin levels in obese; Type 2 diabetic and non-diabetic children. BMC Endocrine Disorders 20:1-9. DOI: 10.1186/s12902-020-00628-y.

Oger F, Gheeraert C, Mogilenko D, Benomar Y, Molendi-Coste O, Bouchaert E, Caron S, Dombrowicz D, Pattou F, Duez H, Eeckhoute J, Staels B, Lefebvre P. 2014. Cell-Specific Dysregulation of MicroRNA Expression in Obese White Adipose Tissue. The Journal of Clinical Endocrinology \& Metabolism 99:2821-2833. DOI: 10.1210/jc.2013-4259.

Ortega FJ, Mercader JM, Catalán V, Moreno-Navarrete JM, Pueyo N, Sabater M, GómezAmbrosi J, Anglada R, Fernández-Formoso JA, Ricart W, Frühbeck G, Fernández-Real JM. 2013. Targeting the circulating microRNA signature of obesity. Clinical Chemistry 59:781792. DOI: 10.1373/clinchem.2012.195776.

Ortega FJ, Mercader JM, Moreno-Navarrete JM, Rovira O, Guerra E, Esteve E, Xifra G, Martínez C, Ricart W, Rieusset J, Rome S, Karczewska-Kupczewska M, Straczkowski M, 
705

706

707

708

709

710

711

712

713

714

715

716

717

718

719

720

721

722

723

724

725

726

727

728

729

730

731

732

733

734

735

736

737

738

739

740

741

742

743

744

745

746

747

748

749

750

Fernández-Real JM. 2014. Profiling of circulating microRNAs reveals common microRNAs linked to type 2 diabetes that change with insulin sensitization. Diabetes Care 37:1375-1383. DOI: 10.2337/dc13-1847.

Peng C, Wang YL. 2018. Editorial: MicroRNAs as new players in endocrinology. Frontiers in Endocrinology 9. DOI: 10.3389/fendo.2018.00459.

Perez-Diaz S, Garcia-Sobreviela MP, Gonzalez-Irazabal Y, Garcia-Rodriguez B, Espina S, Arenaz I, Arbones-Mainar JM. 2018. PTRF acts as an adipokine contributing to adipocyte dysfunctionality and ectopic lipid deposition. Journal of Physiology and Biochemistry 74:613-622. DOI: 10.1007/s13105-018-0638-9.

$\mathrm{Pu}$ Y, Veiga-Lopez A. 2017. PPAR $\gamma$ agonist through the terminal differentiation phase is essential for adipogenic differentiation of fetal ovine preadipocytes. Cellular \& Molecular Biology Letters 22:6. DOI: 10.1186/s11658-017-0037-1.

Qin G, Ma J, Huang Q, Yin H, Han J, Li M, Deng Y, Wang B, Hassan W, Shang J. 2018. Isoquercetin improves hepatic lipid accumulation by activating AMPK pathway and suppressing TGF- $\beta$ signaling on an HFD-induced nonalcoholic fatty liver disease rat model. International Journal of Molecular Sciences 19. DOI: 10.3390/ijms19124126.

Quintanilha BJ, Pinto Ferreira LR, Ferreira FM, Neto EC, Sampaio GR, Rogero MM. 2019. Circulating plasma microRNAs dysregulation and metabolic endotoxemia induced by a high-fat high-saturated diet. Clinical Nutrition. DOI: 10.1016/j.clnu.2019.02.042.

Ramzan F, D'Souza RF, Durainayagam BR, Milan AM, Markworth JF, Miranda-Soberanis V, Sequeira IR, Roy NC, Poppitt SD, Mitchell CJ, Cameron-Smith D. 2019. Circulatory miRNA biomarkers of metabolic syndrome. Acta Diabetologica. DOI: 10.1007/s00592019-01406-6.

Sánchez-Lozada LG, Mu W, Roncal C, Sautin YY, Abdelmalek M, Reungjui S, Le M, Nakagawa T, Lan HY, Yu X, Johnson RJ. 2010. Comparison of free fructose and glucose to sucrose in the ability to cause fatty liver. European Journal of Nutrition 49:1-9. DOI: 10.1007/s00394-009-0042-X.

Sangüesa G, Roglans N, Baena M, Velázquez AM, Laguna JC, Alegret M. 2019. mTOR is a key protein involved in the metabolic effects of simple sugars. International Journal of Molecular Sciences 20. DOI: 10.3390/ijms20051117.

Sangüesa G, Roglans N, Montañés JC, Baena M, Velázquez AM, Sánchez RM, Alegret M, Laguna JC. 2018. Chronic Liquid Fructose, but not Glucose, Supplementation Selectively Induces Visceral Adipose Tissue Leptin Resistance and Hypertrophy in Female SpragueDawley Rats. Molecular Nutrition and Food Research 62. DOI: 10.1002/mnfr.201800777.

Shelke GV, Lässer C, Gho YS, Lötvall J. 2014. Importance of exosome depletion protocols to eliminate functional and RNA-containing extracellular vesicles from fetal bovine serum. Journal of Extracellular Vesicles 3. DOI: 10.3402/jev.v3.24783.

Sheludiakova A, Rooney K, Boakes RA. 2012. Metabolic and behavioural effects of sucrose and fructose/glucose drinks in the rat. European Journal of Nutrition 51:445-454. DOI: 10.1007/s00394-011-0228-x.

Shi C, Pang L, Ji C, Wang J, Lin N, Chen J, Chen L, Yang L, Huang F, Zhou Y, Guo X, Liang H, Zhang M. 2016. Obesity-associated miR-148a is regulated by cytokines and adipokines via a transcriptional mechanism. Molecular Medicine Reports 14:5707-5712. DOI: 10.3892/mmr.2016.5940.

Shi C, Zhang M, Tong M, Yang L, Pang L, Chen L, Xu G, Chi X, Hong Q, Ni Y, Ji C, Guo X. 2015a. miR-148a is Associated with Obesity and Modulates Adipocyte Differentiation of

Peer) reviewing PDF | (2020:10:53327:1:0:CHECK 2 Mar 2021) 
751

752

753

754

755

756

757

758

759

760

761

762

763

764

765

766

767

768

769

770

771

772

773

774

775

776

777

778

779

780

781

782

783

784

785

786

787

788

789

790

791

792

793

794

795

796

Mesenchymal Stem Cells through Wnt Signaling. Scientific reports 5:9930. DOI: 10.1038/srep09930.

Shi C, Zhang M, Tong M, Yang L, Pang L, Chen L, Xu G, Chi X, Hong Q, Ni Y, Ji C, Guo X. 2015b. MiR-148a is associated with obesity and modulates adipocyte differentiation of mesenchymal stem cells through wnt signaling. Scientific Reports 5:1-11. DOI: 10.1038/srep09930.

Shurtleff MJ, Temoche-Diaz MM, Karfilis K V., Ri S, Schekman R. 2016. Y-box protein 1 is required to sort microRNAs into exosomes in cells and in a cell-free reaction. eLife 5. DOI: 10.7554/eLife. 19276 .

Sud N, Zhang H, Pan K, Cheng X, Cui J, Su Q. 2017. Aberrant expression of microRNA induced by high-fructose diet: implications in the pathogenesis of hyperlipidemia and hepatic insulin resistance. Journal of Nutritional Biochemistry 43:125-131. DOI: 10.1016/j.jnutbio.2017.02.003.

Sugimoto K, Hosotani T, Kawasaki T, Nakagawa K, Hayashi S, Nakano Y, Inui H, Yamanouchi T. 2010. Eucalyptus leaf extract suppresses the postprandial elevation of portal, cardiac and peripheral fructose concentrations after sucrose ingestion in rats. Journal of Clinical Biochemistry and Nutrition 46:205-211. DOI: 10.3164/jcbn.09-93.

Thomou T, Mori MA, Dreyfuss JM, Konishi M, Sakaguchi M, Wolfrum C, Rao TN, Winnay JN, Garcia-Martin R, Grinspoon SK, Gorden P, Kahn CR. 2017. Adipose-derived circulating miRNAs regulate gene expression in other tissues. Nature 542:450-455. DOI: 10.1038 /nature21365.

Toop CR, Gentili S. 2016. Fructose beverage consumption induces a metabolic syndrome phenotype in the rat: A systematic review and meta-analysis. Nutrients 8. DOI: $10.3390 /$ nu8090577.

Valapala M, Vishwanatha JK. 2011. Lipid raft endocytosis and exosomal transport facilitate extracellular trafficking of annexin A2. Journal of Biological Chemistry 286:30911-30925. DOI: $10.1074 /$ jbc.M111.271155.

Wang R, Hong J, Cao Y, Shi J, Gu W, Ning G, Zhang Y, Wang W. 2015a. Elevated circulating microRNA-122 is associated with obesity and insulin resistance in young adults. European Journal of Endocrinology 172:291-300. DOI: 10.1530/EJE-14-0867.

Wang T, Li M, Guan J, Li P, Wang H, Guo Y, Shuai S, Li X. 2011. MicroRNAs miR-27a and miR-143 regulate porcine adipocyte lipid metabolism. International Journal of Molecular Sciences 12:7950-7959. DOI: 10.3390/ijms12117950.

Wang L, Xu L, Xu M, Liu G, Xing J, Sun C, Ding H. 2015b. Obesity-associated MiR-342-3p promotes adipogenesis of mesenchymal stem cells by suppressing CtBP2 and releasing $\mathrm{C} / \mathrm{EBP} \alpha$ from CtBP2 binding. Cellular Physiology and Biochemistry 35:2285-2298. DOI: $10.1159 / 000374032$.

Wang T, Yan R-Q, Cao J, Cao L-L, Zhang X-P, Li X-N, Wu P, Zhou X-O, Wu J-F, Xu X-Y. 2016. [Expression of miR-140-5p and prediction of its target gene in human mesenchymal stem cells during adipogenic differentiation]. Nan fang yi ke da xue xue bao = Journal of Southern Medical University 37:199-203.

Wei C, Meng L, Zhang Y. 2020. miR-450a-5p eliminates MGO-induced insulin resistance via targeting CREB. International Journal of Stem Cells 13:46-54. DOI: 10.15283/ijsc19088.

Wen D, Qiao P, Wang L. 2015. Circulating microRNA-223 as a potential biomarker for obesity. Obesity Research and Clinical Practice 9:398-404. DOI: 10.1016/j.orcp.2015.01.006.

Xie H, Lim B, Lodish HF. 2009. MicroRNAs Induced During Adipogenesis that Accelerate Fat

Peer) reviewing PDF | (2020:10:53327:1:0:CHECK 2 Mar 2021) 
797

798

799

800

801

802

803

804

805

806

807

808

809

810

811

812

813

814

815

816

817

818

819

820

821

822

823

824

825

826
Cell Development Are Downregulated in Obesity. Diabetes 58:1050-1057. DOI:

10.2337/db08-1299.

Yerlikaya FH, Mehmet Ö. 2019. Aberrant expression of miRNA profiles in high-fat and highsucrose fed rats. Clinical Nutrition Experimental. DOI: 10.1016/j.yclnex.2019.07.001.

Zampetaki A, Kiechl S, Drozdov I, Willeit P, Mayr U, Prokopi M, Mayr A, Weger S, Oberhollenzer F, Bonora E, Shah A, Willeit J, Mayr M. 2010. Plasma MicroRNA profiling reveals loss of endothelial MiR-126 and other MicroRNAs in type 2 diabetes. Circulation Research 107:810-817. DOI: 10.1161/CIRCRESAHA.110.226357.

Zhang X, Chang A, Li Y, Gao Y, Wang H, Ma Z, Li X, Wang B. 2016. miR-140-5p regulates adipocyte differentiation by targeting transforming growth factor- $\beta$ signaling. Scientific Reports 5:18118. DOI: 10.1038/srep18118.

Zhang Y, Yu M, Dai M, Chen C, Tang Q, Jing W, Wang H, Tian W. 2017. miR-450a-5p within rat adipose tissue exosome-like vesicles promotes adipogenic differentiation by targeting WISP2. Journal of Cell Science:jcs.197764. DOI: 10.1242/jcs.197764.

Zhu YL, Chen T, Xiong JL, Wu D, Xi QY, Luo JY, Sun JJ, Zhang YL. 2018. miR-146b inhibits glucose consumption by targeting IRS1 gene in porcine primary adipocytes. International Journal of Molecular Sciences 19. DOI: 10.3390/ijms 19030783.

Zhuang G, Meng C, Guo X, Cheruku PS, Shi L, Xu H, Li H, Wang G, Evans AR, Safe S, Wu C, Zhou B. 2012. A novel regulator of macrophage activation: MiR-223 in obesity-associated adipose tissue inflammation. Circulation 125:2892-2903. DOI: 10.1161/CIRCULATIONAHA.111.087817.

Zubiría MG, Alzamendi A, Moreno G, Rey MA, Spinedi E, Giovambattista A. 2016a. Long-term fructose intake increases adipogenic potential: Evidence of direct effects of fructose on adipocyte precursor cells. Nutrients 8. DOI: 10.3390/nu8040198.

Zubiría M, Alzamendi A, Moreno G, Rey M, Spinedi E, Giovambattista A. 2016b. Long-Term Fructose Intake Increases Adipogenic Potential: Evidence of Direct Effects of Fructose on Adipocyte Precursor Cells. Nutrients 8:198. DOI: 10.3390/nu8040198. 
Table $\mathbf{1}$ (on next page)

Selection of microRNAs 


\begin{tabular}{|c|c|c|}
\hline miRNA & Function & Reference \\
\hline miR-21-5p & $\begin{array}{l}\text { Increased in total plasma fructose-fed mice. Regulated adipogenesis in 3T3-L1 cells. } \\
\text { Increased in adipose tissue of obese, in adipose tissue of T2DM patients. }\end{array}$ & $\begin{array}{l}\text { (Kang et al., 2013; Engin, 2017; } \\
\text { Guglielmi et al., 2017) }\end{array}$ \\
\hline miR-146b-5p & $\begin{array}{l}\text { Increased in total plasma of obese patients. Regulated adipogenesis in 3T3-L1 cells and } \\
\text { regulate glucose metabolism in adipocytes. Increased in adipose tissue of obese. }\end{array}$ & $\begin{array}{l}\text { (Chen et al., 2014; Cui et al., 2018; } \\
\text { Zhu et al., 2018) }\end{array}$ \\
\hline $\operatorname{miR}-140-5 p$ & Increase in total plasma of obese and T2DM. Regulated adipogenesis in 3T3-L1 cells. & $\begin{array}{l}\text { (Ortega et al., 2013, 2014; Wang et } \\
\text { al., 2015a; Li et al., 2017) }\end{array}$ \\
\hline miR-143-5p & $\begin{array}{l}\text { Increased in total plasma of obese. Regulated adipogenesis in human adipocytes and } \\
\text { 3T3-L1 cells, and regulated lipid accumulationin 3T3-L1 cells. }\end{array}$ & $\begin{array}{l}\text { (Esau et al., 2004; Xie, Lim \& } \\
\text { Lodish, 2009; Wang et al., 2011; } \\
\text { Quintanilha et al., 2019) }\end{array}$ \\
\hline $\operatorname{miR}-342-3 p$ & $\begin{array}{l}\text { Decreased in total plasma of obese and in total plasma of insulin-resistant subjects. } \\
\text { Regulated adipogenesis in 3T3-L1 cells, and lipogenesis non-adipocyte cells. }\end{array}$ & $\begin{array}{l}\text { (Li et al., 2013; Wang et al., } \\
\text { 2015b,a; Khalyfa et al., 2016; } \\
\text { Masotti et al., 2017) }\end{array}$ \\
\hline miR-223-3p & $\begin{array}{l}\text { Decrease in total plasma of obese, in total plasma of T2DM patients, and increased in } \\
\text { EVs of sucrose-fed rats. Regulated adipogenesis in mesenchymal stem cells. } \\
\text { in insulin resistance human adipose tissue and inflammatory response. }\end{array}$ & $\begin{array}{l}\text { (Zampetaki et al., 2010; } \\
\text { Bauernfeind et al., 2012; Chuang et } \\
\text { al., 2015; Kilic et al., 2015; Wen, } \\
\text { Qiao \& Wang, 2015; Guan et al., } \\
\text { 2015; Brianza-Padilla et al., 2016) }\end{array}$ \\
\hline miR-450a-5p & $\begin{array}{l}\text { Regulated adipogenesis in } 3 \text { T3-L1 cells mediated by exosome-like vesicles. Increased in } \\
\text { insulin resistance in HUVEC cells. }\end{array}$ & $\begin{array}{l}\text { (Zhang et al., 2017; Wei, Meng \& } \\
\text { Zhang, 2020) }\end{array}$ \\
\hline miR-148a-5p & $\begin{array}{l}\text { Regulated adipogenesis in 3T3-L1 cells. Decrease in inflammatory response in human } \\
\text { adipose tissue-derived mesenchymal stem cells. }\end{array}$ & (Shi et al., 2015, 2016) \\
\hline
\end{tabular}




\section{Table 2 (on next page)}

Expression of adipocyte-related miRNAs in EVs and 3T3-L1 cells.

miRNAs expression was determined by RT-qPCR using cel-miR-39 as reference for EVs and U6 as reference for cells for the $2^{-\Delta c t}$ method. Differences were tested by the Mann-Whitney U test. Data are presented as means $\pm \mathrm{SE}$. 


\begin{tabular}{|c|c|c|c|c|c|c|c|}
\hline & Control $(n=5)$ & Ct Control & Fru $550 \mu M(n=5)$ & Ct Fru $550 \mu \mathrm{M}$ & Fold change & P-value & Ct P-value \\
\hline \multicolumn{8}{|c|}{ Extracellular vesicles } \\
\hline $\operatorname{miR}-21-5 p$ & $0.0063 \pm 0.0014$ & $26.89 \pm 1.05$ & $0.0175 \pm 0.0079$ & $25.75 \pm 0.96$ & 2.777 & 0.2857 & 0.5556 \\
\hline miR-146b-5p & $0.0002 \pm 4.21 \mathrm{e}^{-5}$ & $30.17 \pm 0.20$ & $0.0012 \pm 0.0009$ & $31.06 \pm 3.09$ & 6.000 & 0.6286 & 0.6286 \\
\hline $\operatorname{mir}-140-5 p$ & $0.0002 \pm 7.88 \mathrm{e}^{-5}$ & $30.38 \pm 0.45$ & $0.0014 \pm 0.0013$ & $29.64 \pm 1.42$ & 7.000 & 0.8571 & 0.8571 \\
\hline $\operatorname{mir}-143-5 p$ & $0.0009 \pm 0.0002$ & $29.76 \pm 1.09$ & $0.0034 \pm 0.0012$ & $27.92 \pm 1.06$ & 3.777 & 0.0286 & 0.3429 \\
\hline $\operatorname{miR}-342-3 p$ & $7.57 \mathrm{e}^{-5} \pm 1.37 \mathrm{e}^{-5}$ & $33.43 \pm 0.26$ & $0.0001 \pm 3.04 \mathrm{e}^{-5}$ & $32.88 \pm 0.29$ & 1.321 & 0.6286 & 0.2286 \\
\hline $\operatorname{miR}-223-3 p$ & $0.0006 \pm 0.0002$ & $31.15 \pm 0.31$ & $0.0001 \pm 4.14 \mathrm{e}^{-5}$ & $31.42 \pm 0.56$ & -6.000 & 0.0286 & 0.8857 \\
\hline miR-450a-5p & $1.66 \mathrm{e}^{-6} \pm 1.01 \mathrm{e}^{-6}$ & $37.72 \pm 0.83$ & $5.75 \mathrm{e}^{-6} \pm 4.25 \mathrm{e}^{-6}$ & $36.42 \pm 0.89$ & 3.463 & 0.4000 & 0.4000 \\
\hline miR-148a-5p & $1.33 \mathrm{e}^{-5} \pm 8.08 \mathrm{e}^{-6}$ & $34.71 \pm 0.82$ & $1.72 \mathrm{e}^{-5} \pm 5.39 \mathrm{e}^{-6}$ & $34.00 \pm 0.52$ & 1.293 & 0.4000 & 0.4000 \\
\hline \multicolumn{8}{|l|}{ 3T3-L1 cells } \\
\hline $\operatorname{miR}-21-5 p$ & $1.0000 \pm 0.0281$ & $18.18 \pm 0.06$ & $1.2290 \pm 0.2199$ & $18.24 \pm 0.02$ & 1.229 & 0.8413 & 0.5476 \\
\hline miR-146b-5p & $0.1386 \pm 0.0016$ & $21.03 \pm 0.04$ & $0.1736 \pm 0.0198$ & $21.59 \pm 0.60$ & 1.252 & 0.0411 & 0.9999 \\
\hline miR-140-5p & $0.0308 \pm 0.0010$ & $23.20 \pm 0.06$ & $0.0438 \pm 0.0072$ & $23.04 \pm 0.02$ & 1.422 & 0.0079 & 0.0556 \\
\hline miR-143-5p & $0.0093 \pm 0.0004$ & $24.96 \pm 0.11$ & $0.0126 \pm 0.0011$ & $24.79 \pm 0.10$ & 1.354 & 0.0179 & 0.3929 \\
\hline $\operatorname{miR}-342-3 p$ & $0.0018 \pm 9.95 \mathrm{e}^{-5}$ & $27.25 \pm 0.10$ & $0.0031 \pm 0.0006$ & $26.93 \pm 0.04$ & 1.722 & 0.0159 & 0.0317 \\
\hline $\operatorname{miR}-223-3 p$ & $0.0007 \pm 6.16 \mathrm{e}^{-5}$ & $28.51 \pm 0.15$ & $0.0016 \pm 0.0005$ & $27.92 \pm 0.18$ & 2.285 & 0.0079 & 0.0079 \\
\hline miR-450a-5p & $0.0003 \pm 1.71 \mathrm{e}^{-5}$ & $29.88 \pm 0.10$ & $0.0003 \pm 6.69 \mathrm{e}^{-5}$ & $29.87 \pm 0.09$ & 1.000 & 0.8889 & 0.9999 \\
\hline miR-148a-5p & $4.60 \mathrm{e}^{-6} \pm 4.78 \mathrm{e}^{-7}$ & $35.94 \pm 0.15$ & $5.59 \mathrm{e}^{-6} \pm 8.58 \mathrm{e}^{-7}$ & $35.76 \pm 0.11$ & 1.215 & 0.7302 & 0.5556 \\
\hline
\end{tabular}




\section{Table 3(on next page)}

Biochemical data in Control and Fructose group.

Differences were tested by the Mann-Whitney $U$ test. Data are presented as means $\pm \mathrm{SE}$. 
1

\begin{tabular}{lccc}
\hline & Control $(\mathbf{n}=\mathbf{6})$ & Fructose $(\mathbf{n}=\mathbf{1 4})$ & P-Value \\
\hline Body weight $(\mathrm{g})$ & $350.20 \pm 15.21$ & $341.9 \pm 5.92$ & 0.792 \\
Epididymal Adipose tissue weight $(\mathrm{g})$ & $2.51 \pm 0.19$ & $2.95 \pm 0.14$ & 0.148 \\
Average of adipocyte area $\left(\mu \mathrm{m}^{2}\right)$ & $1620 \pm 52.29$ & $2090 \pm 105.6$ & 0.039 \\
Glucose $(\mathrm{mg} / \mathrm{dL})$ & $160.70 \pm 8.95$ & $232.50 \pm 17.89$ & 0.001 \\
Insulin $(\mathrm{pg} / \mathrm{mL})$ & $16.49 \pm 2.42$ & $44.9 \pm 4.65$ & 0.007 \\
HOMA-IR & $0.270 \pm 0.04$ & $0.870 \pm 0.15$ & 0.007 \\
Total Cholesterol $(\mathrm{mg} / \mathrm{dL})$ & $47.98 \pm 1.67$ & $48.92 \pm 1.29$ & 0.920 \\
Triglycerides $(\mathrm{mg} / \mathrm{dL})$ & $53.83 \pm 7.56$ & $125.30 \pm 16.15$ & 0.001 \\
HDL-Cholesterol $(\mathrm{mg} / \mathrm{dL})$ & $38.98 \pm 1.87$ & $33.88 \pm 1.51$ & 0.042 \\
Leptin $(\mathrm{pg} / \mathrm{mL})$ & $902.70 \pm 208.5$ & $1751 \pm 160.2$ & 0.012 \\
Adiponectin $(\mathrm{ng} / \mathrm{mL})$ & $52.42 \pm 3.08$ & $72.17 \pm 4.12$ & 0.017 \\
IL-1 $\beta(\mathrm{pg} / \mathrm{mL})$ & $19.59 \pm 10.27$ & $107.70 \pm 29.59$ & 0.033 \\
\hline
\end{tabular}

2 


\section{Table 4 (on next page)}

Expression of adipocyte-related miRNAs in EVs and adipose tissue.

miRNAs expression was determined by RT-qPCR using cel-miR-39 as reference for EVs and U6 as reference for cells for the $2^{-\Delta c t}$ method. Differences were tested by the Mann-Whitney U test. Data are presented as means $\pm \mathrm{SE}$. 


\begin{tabular}{|c|c|c|c|c|c|c|c|}
\hline & Control $(n=6)$ & Ct Control & Fructose $(n=14)$ & Ct Fructose & Fold change & P-value & Ct P-value \\
\hline \multicolumn{8}{|c|}{ Extracellular vesicles } \\
\hline $\operatorname{miR}-21-5 p$ & $0.8459 \pm 0.1206$ & $21.55 \pm 0.28$ & $0.3688 \pm 0.1570$ & $24.18 \pm 0.60$ & -2.293 & 0.1093 & 0.1528 \\
\hline $\operatorname{miR}-223-3 p$ & $4.9440 \pm 0.4456$ & $18.95 \pm 0.14$ & $1.2750 \pm 0.6552$ & $23.01 \pm 0.70$ & -3.877 & 0.0220 & 0.0167 \\
\hline miR-450a-5p & $0.0006 \pm 0.0001$ & $32.13 \pm 0.49$ & $0.0005 \pm 9.632 \mathrm{e}^{-5}$ & $30.89 \pm 0.14$ & -1.200 & 0.7181 & 0.0064 \\
\hline miR-140-5p & $0.0810 \pm 0.0099$ & $24.89 \pm 0.15$ & $0.0174 \pm 0.0100$ & $27.37 \pm 0.38$ & -4.655 & 0.0129 & 0.0135 \\
\hline miR-146b-5p & $0.0235 \pm 0.0021$ & $26.66 \pm 0.14$ & $0.0055 \pm 0.0036$ & $30.88 \pm 0.68$ & -4.272 & 0.0245 & 0.0245 \\
\hline $\operatorname{miR}-143-5 p$ & $0.0014 \pm 0.0005$ & $31.42 \pm 0.86$ & $0.0142 \pm 0.0017$ & $26.22 \pm 0.51$ & 10.142 & 0.0010 & 0.0010 \\
\hline miR-342-3p & $0.0483 \pm 0.0046$ & $25.62 \pm 0.13$ & $0.0051 \pm 0.0041$ & $28.92 \pm 0.35$ & -9.470 & 0.0011 & 0.0011 \\
\hline miR-148a-5p & $1.714 \mathrm{e}^{-5} \pm 4.490 \mathrm{e}^{-6}$ & $37.42 \pm 0.57$ & $3.024 \mathrm{e}^{-5} \pm 5.187 \mathrm{e}^{-6}$ & $35.17 \pm 0.29$ & 1.764 & 0.1250 & 0.0010 \\
\hline \multicolumn{8}{|l|}{ Adipose tissue } \\
\hline miR-21-5p & $0.4912 \pm 0.0749$ & $20.17 \pm 0.21$ & $0.4342 \pm 0.0378$ & $20.04 \pm 0.11$ & -1.131 & 0.5214 & 0.8314 \\
\hline miR-223-3p & $0.1674 \pm 0.0200$ & $21.69 \pm 0.13$ & $0.1297 \pm 0.0061$ & $21.74 \pm 0.06$ & -1.290 & 0.0462 & 0.8983 \\
\hline $\operatorname{miR}-450 a-5 p$ & $0.0299 \pm 0.0024$ & $24.15 \pm 0.07$ & $0.0297 \pm 0.0018$ & $23.88 \pm 0.07$ & -1.004 & 0.8314 & 0.0462 \\
\hline miR-140-5p & $0.0301 \pm 0.0058$ & $24.24 \pm 0.23$ & $0.0278 \pm 0.0019$ & $23.99 \pm 0.10$ & 1.083 & 0.8983 & 0.4155 \\
\hline miR-146b-5p & $0.0118 \pm 0.0019$ & $25.55 \pm 0.22$ & $0.0112 \pm 0.0006$ & $25.28 \pm 0.07$ & -1.050 & 0.7166 & 0.2818 \\
\hline $\operatorname{miR}-143-5 p$ & $0.0118 \pm 0.0008$ & $25.42 \pm 0.16$ & $0.0214 \pm 0.0030$ & $24.45 \pm 0.17$ & 1.816 & 0.0143 & 0.0034 \\
\hline $\operatorname{miR}-342-3 p$ & $0.0086 \pm 0.0009$ & $25.96 \pm 0.21$ & $0.0066 \pm 0.0011$ & $26.14 \pm 0.22$ & -1.305 & 0.0320 & 0.2908 \\
\hline miR-148a-5p & $0.0001 \pm 3.925 \mathrm{e}^{-5}$ & $31.81 \pm 0.30$ & $0.0001 \pm 1.369 \mathrm{e}^{-5}$ & $31.76 \pm 0.13$ & -1.230 & 0.6865 & 0.8314 \\
\hline
\end{tabular}




\section{Figure 1}

Particle number estimation and size of EVs derived from supernatants from 3T3-L1 cells and rat plasma.

a) The total number of particles from 3T3-L1 cells supernatants was estimated by nanoparticle tracking analysis. b) The mean size of EVs from 3T3-L1 cells supernatants. c) Western blot for CD63, ANXA2, and CD81 in EVs of 3T3-L1 cell supernatants. d) The total number of particles from rat plasma was estimated by nanoparticle tracking analysis. e) The mean size of EVs from rat plasma. Differences were tested by the Mann-Whitney U test. Data are presented as means $\pm \mathrm{SE}$. 
a)

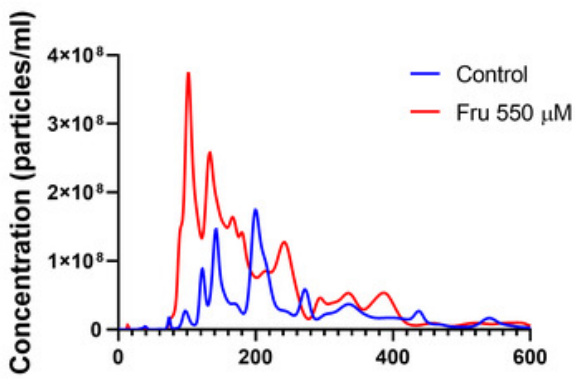

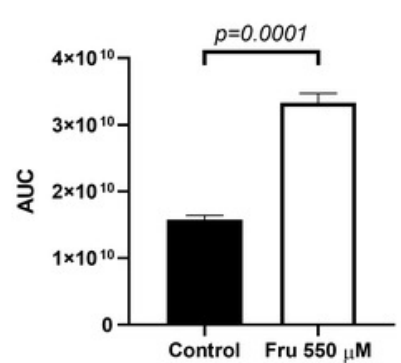

b)

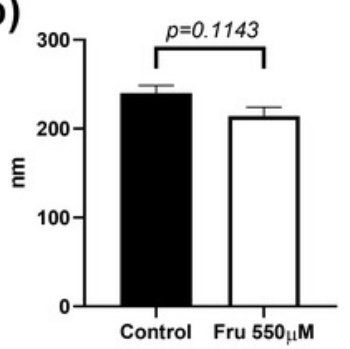

c)
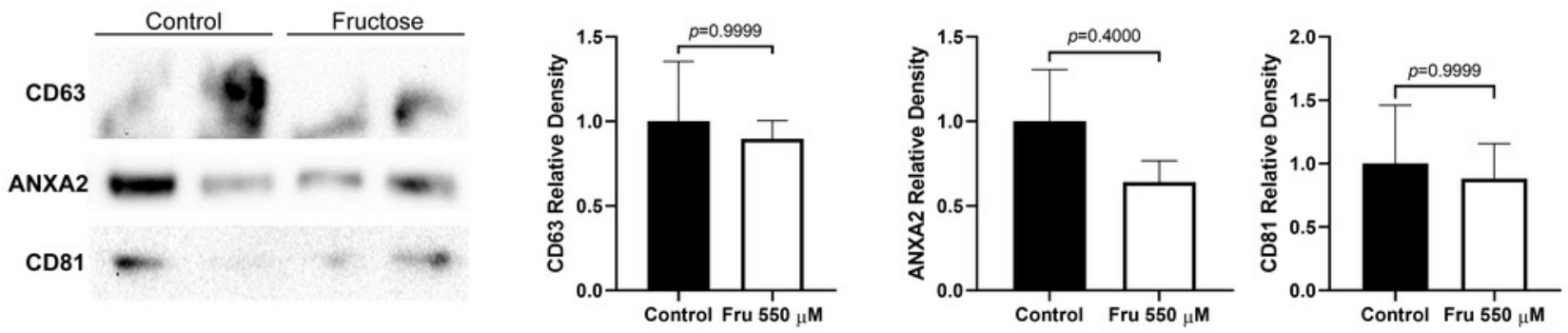

d)
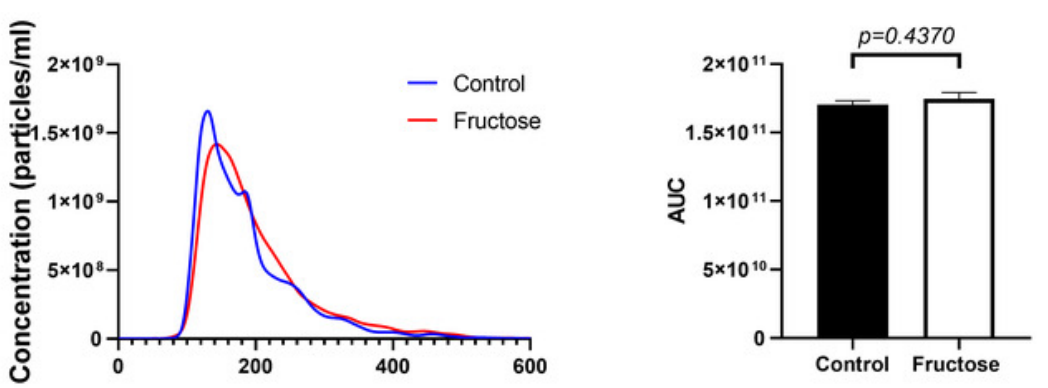

e)

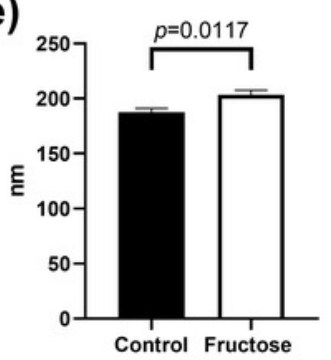


Figure 2

Fructose exposure modified the levels of miR-143-5p and miR-223-3p in EVs, 3T3-L1 cells, and adipose tissue.

a) Levels of miR-143-5p (black), miR-223-3p (grey) and miR-342-3p (light grey) in EVs from 3T3-L1 cells supernatant. b) Levels of miR-143-5p (black), miR-223-3p (grey) and miR-342-3p (light grey) in EVs from rat plasma. c) Expression of miR-143-5p (black), miR-223-3p (grey) and miR-342-3p (light grey) in 3T3-L1 cells. d) Expression of miR-143-5p (black), miR-223-3p (grey) and miR-342-3p (light grey) in rat adipose tissue. Differences were tested by the Mann-Whitney U test. Data are presented as means $\pm \mathrm{SE}$.

a)

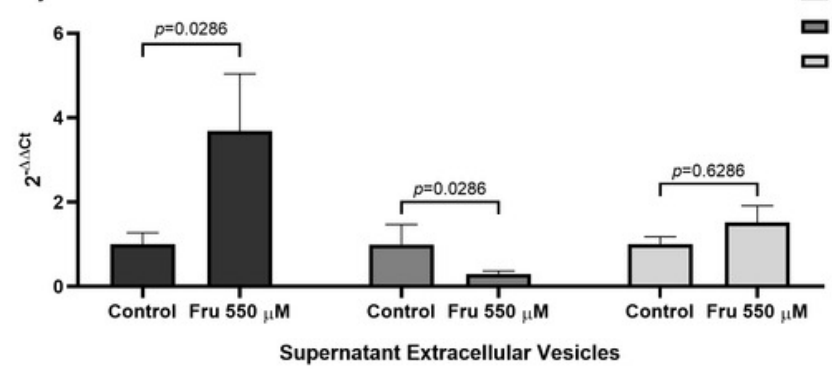

c)

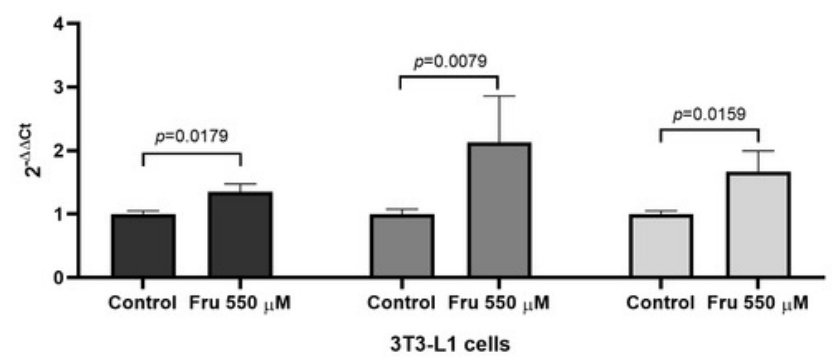

b)

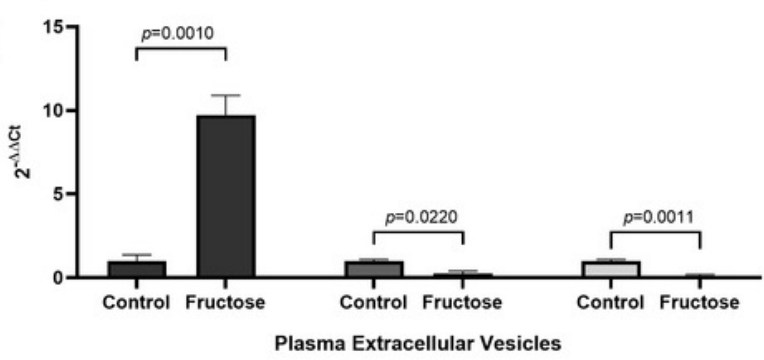

d)

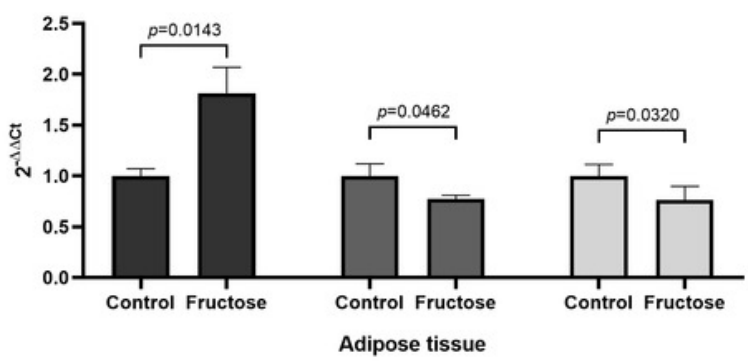

